\title{
REDCAPP (v1.0): parameterizing valley inversions in air temperature data downscaled from reanalyses
}

\author{
Bin Cao ${ }^{1,2}$, Stephan Gruber ${ }^{2}$, and Tingjun Zhang ${ }^{1}$ \\ ${ }^{1}$ Key Laboratory of Western China's Environmental Systems (MOE), College of Earth and Environmental Sciences, \\ Lanzhou University, Lanzhou 730000, China \\ ${ }^{2}$ Department of Geography \& Environmental Studies, Carleton University, Ottawa, K1S 5B6, Canada \\ Correspondence to: Bin Cao (caob08@1zu.edu.cn)
}

Received: 9 March 2017 - Discussion started: 24 April 2017

Revised: 26 June 2017 - Accepted: 2 July 2017 - Published: 1 August 2017

\begin{abstract}
In mountain areas, the use of coarse-grid reanalysis data for driving fine-scale models requires downscaling of near-surface (e.g., $2 \mathrm{~m}$ high) air temperature. Existing approaches describe lapse rates well but differ in how they include surface effects, i.e., the difference between the simulated $2 \mathrm{~m}$ and upper-air temperatures. We show that different treatment of surface effects result in some methods making better predictions in valleys while others are better in summit areas. We propose the downscaling method REDCAPP (REanalysis Downscaling Cold Air Pooling Parameterization) with a spatially variable magnitude of surface effects. Results are evaluated with observations (395 stations) from two mountain regions and compared with three reference methods. Our findings suggest that the difference between near-surface air temperature and pressure-level temperature $(\Delta T)$ is a good proxy of surface effects. It can be used with a spatially variable land-surface correction factor (LSCF) for improving downscaling results, especially in valleys with strong surface effects and cold air pooling during winter. While LSCF can be parameterized from a fine-scale digital elevation model (DEM), the transfer of model parameters between mountain ranges needs further investigation.
\end{abstract}

\section{Introduction}

Air temperature $(T)$ controls a variety of environmental processes (Jones and Kelly, 1983). Predicting $T$ at fine scale, however, is challenging in hilly and mountainous terrain because the lateral variability of $T$ is larger and subject to a greater diversity of processes than in gentle terrain. Direct observations of $T$ are usually sparse in mountains (Daly, 2006; Minder et al., 2010) and correspondingly, their interpolation is often not a reliable basis for estimating $T$ over larger areas. Atmospheric reanalyses, which are produced by assimilating observational data into numerical weather prediction model runs (Kistler et al., 2001; Dee et al., 2011; Harris et al., 2014), are a valuable alternative as their output is available on regular grids. In order to make predictions at the fine scale $(\sim 10-100 \mathrm{~m})$, required for representing topography, the coarse-scale $(\sim 10-100 \mathrm{~km})$ reanalysis data need to be downscaled (Bürger et al., 2012). Previous studies (Fiddes and Gruber, 2014; Gupta and Tarboton, 2016; Gao et al., 2012) have reported how reanalysis data can be used to represent the elevation dependency of $T$ in downscaling. This study investigates how to further refine corresponding predictions and outlines a REanalysis Downscaling Cold Air Pooling Parameterization (REDCAPP) method.

Approaches for downscaling can be classified as (1) dynamical, using physically based models, and (2) statistical, using empirical-statistical relationships (Bürger et al., 2012). Typically, regional climate models (RCMs) are used for dynamical downscaling aimed at deriving fine-scale data consistent with large-scale climate fields. As RCMs are computationally expensive, their spatial resolution is often restricted to $\sim 1-10 \mathrm{~km}$ (Hay and Clark, 2003; Maraun et al., 2010; Hagemann et al., 2004). Additionally, the lack of appropriate parameterizations or numerical methods often restricts how finely resolved RCMs can be run in mountains (Kiefer and Zhong, 2015). Statistical methods make fine-scale predictions based on statistical or empirical relationships between observations and coarse-scale fields 
(Yang et al., 2012). Statistical downscaling usually is computationally efficient (Chu et al., 2010; Hofer et al., 2010; Souvignet et al., 2010) but the requirement for observations inherent in many methods limits their applicability to mountains and remote areas.

A number of downscaling methods have been proposed that rely on physically based empirical-statistical relationships and thus do not require local station data (Fiddes and Gruber, 2014; Gao et al., 2012). The basic assumption of these methods is that vertical gradients imposed by topography are more important than horizontal ones. The simplest method, here referred to as REF1 (reference method 1), uses a fixed lapse rate, usually $-6.5^{\circ} \mathrm{C} \mathrm{km}^{-1}$ (Dimri, 2009; Giorgi et al., 2003), for describing the elevation dependence of $T$. Lapse rates are reported to be variable (Giorgi et al., 2003; Lundquist and Cayan, 2007) and many of the drivers of this variability are represented in reanalysis models. Upperair temperature, described at different pressure levels $\left(T_{\mathrm{pl}}\right)$ in reanalyses, has been used to derive average lapse rates over large areas through linear regression against geopotential or elevation (Mokhov and Akperov, 2006; Gruber, 2012). Recently, Fiddes and Gruber (2014) presented $T$ downscaling through direct interpolation of $T_{\mathrm{pl}}$ (REF2), and Gao et al. (2012) obtained fine-scale $T$ by adding a lapse rate derived from $T_{\mathrm{pl}}$ to surface air temperature $\left(T_{\mathrm{sa}}\right)(\mathrm{REF} 3)$.

While REF2 and REF3 have achieved some successes due to the strong and well-described influence of elevation on $T$, they differ in their treatment of surface effects. The ground surface warms or cools near-surface air with respect to the upper-air temperature. For this reason, reanalyses provide separate variables for $T_{\mathrm{sa}}$ (surface air temperature) and $T_{\mathrm{pl}}$ (upper-air temperature at several pressure levels). Surface effects in mountains, however, are spatially heterogeneous. It is obvious that a peak, having only a small area of ground surfaces in proximity, will on average be subject to much weaker surface effects than a valley. Additionally, during periods of strong radiative cooling, the lateral drainage of cold air can lead to cold air pooling (CAP) in valley bottoms, further differentiating surface effects spatially. For example, Lewkowicz and Bonnaventure (2011) reported that $T$ in valleys is lower than at higher locations in mountains due to strong winter inversion. In the reference methods, surface effects on $T$ are either ignored (REF2) or treated as spatially invariant at the fine scale (REF1 and REF3). It is thus desirable to find a way to describe the spatial and temporal patterns of surface effects in mountainous terrain and to incorporate them into downscaling parameterization schemes.

In this study, we describe and test a method (REDCAPP) for parameterizing the temporal and spatial differentiation of surface effects and cold air pooling when downscaling reanalysis data in mountainous areas. The method is based on deriving a proxy of surface effects $(\Delta T)$ from reanalysis data and then adding it, in spatially varying amounts, to the finescale air temperature derived from pressure levels. This is accomplished with a land-surface correction factor (LSCF) estimated based on terrain morphometry. Specifically, we address four research questions:

1. Is $\Delta T$ suitable for parameterizing CAP and surface effects?

2. How well can we estimate LSCF from a fine-scale digital elevation model (DEM)?

3. How much does REDCAPP improve downscaling when compared with reference methods?

4. Can REDCAPP parameters easily be transferred between different mountain ranges?

In this study, we describe REDCAPP and its application with ERA-Interim data. We investigate patterns of $\Delta T$ spatially and in time series using differing topographic locations, such as deep valleys, slopes and peaks. We then compare LSCF fitted to station data with estimates derived from fine-scale DEMs. The performance and transferability of REDCAPP are evaluated using a large number of observations from the Swiss Alps and the Chinese Qilian Mountains in the northeast of the Qinghai-Tibetan Plateau.

\section{Background}

\subsection{Near-surface and upper-air temperature}

In this study, the difference between near-surface air temperature $T_{\mathrm{sa}}$ and upper-air temperature $T_{\mathrm{pl}}$ is important. Upper air refers to the portion of atmosphere well above the Earth's surface, which is gently stirred towards the large-scale forcing field and in which the effects of the land-surface friction on the air motion are negligible (Van De Berg and Medley, 2016). In reanalyses, upper-air variables are typically available at discrete vertical levels defined in terms of air pressure and ranging from near sea level to tens of kilometers in height. This makes $T_{\mathrm{pl}}$ a four-dimensional variable (longitude, latitude, pressure level, time) and it is given also at pressure levels corresponding to elevations lower than the model topography. The near-surface air temperature $T_{\mathrm{sa}}$ is directly influenced by the land surface via its energy balance and roughness. Reanalysis data are produced by coupled atmosphere-land-ocean models, which usually represent upper-air temperature and land-surface conditions rather well (Compo et al., 2011). Since $T_{\mathrm{sa}}$ and $T_{\mathrm{pl}}$ are available in reanalysis products, the strength of the simulated landsurface effects on $T_{\mathrm{sa}}$ can be quantified by their difference $(\Delta T)$.

Fiddes and Gruber (2014) interpolate values from pressure levels to obtain the upper-air temperature at the elevation of the fine-scale topography $T_{\mathrm{pl}}^{\mathrm{f}}$. Assuming that in each time step only the magnitude of land-surface effects varies at the fine scale (Jones and Kelly, 1983), $\Delta T$ can be added back to $T_{\mathrm{pl}}^{\mathrm{f}}$ after multiplication with the LSCF. In the following, 
Sect. 2.2 and 2.3 describe the rationale of predicting LSCF from DEM-derived geomorphometric variables.

\subsection{Land-surface effects and hypsometric position}

With increasing altitude, the influence of local circulation is gradually transferred to regional circulation. By consequence, $T$ is more strongly controlled by land-surface effects in low areas such as valley bottoms and almost exclusively by the upper air at high elevations such as mountain peaks (Tabony, 1985). This means hypsometric position can be used as a geomorphometric proxy for the relative strength of land-surface effects. The hypsometric position $[0,1]$ refers to the cumulative density of fine-scale elevation being higher than a given location within a defined surrounding area.

\subsection{Cold air pooling}

CAPs, also known as "valley inversion" or "temperature inversion", occur in topographic depressions, and often the air near the surface is colder there than the air above (Lareau et al., 2013). CAP is caused by downslope flow and accumulation of cold air (Kiefer and Zhong, 2015), usually during periods of strong radiative cooling (Lareau et al., 2013). The temperature inversion can vary from $1{ }^{\circ} \mathrm{C}$ to more than $10^{\circ} \mathrm{C}$ depending on the surrounding terrain (e.g., land cover and valley geometry) and weather situation (Kiefer and Zhong, 2015; Whiteman et al., 2001). CAPs are common in almost all sizes of basins and valleys (Kiefer and Zhong, 2015; Mahrt et al., 2001), and their strength is expected to be related to how low and sheltered valleys are (Lareau et al., 2013). In order to predict CAPs at the fine scale based on $\Delta T$, a geomorphometric variable is needed for identifying valleys and for comparing the "degree of valleyness".

\section{Data}

\subsection{ERA-Interim}

ERA-Interim is a global reanalysis product produced by the European Centre for Medium-Range Weather Forecasts (ECMWF) using a fully coupled atmosphere-ocean-land model and four-dimensional variational assimilation (Berrisford et al., 2011). It has 60 pressure levels in the vertical, with the top level at $1 \mathrm{mb}$. A reduced Gaussian grid with approximately uniform $79 \mathrm{~km}$ spacing for surface and other gridpoint fields is used. ERA-Interim data cover the period from 1 January 1979 onward and are extended with current observations with little delay (Dee et al., 2011). ERA-Interim produces four analyses per day at 00:00, 06:00, 12:00 and 18:00 UTC for the surface and 60 pressure levels in the upper atmosphere. ERA-Interim has been evaluated for various mountain regions via field measurements and proved to resolve large-scale climate well (Bao and Zhang, 2013; Mugford et al., 2012; Fiddes et al., 2015; Hodges et al., 2011;
Table 1. Summary of observational stations used.

\begin{tabular}{llr}
\hline Region & Data source & Number of stations \\
\hline Swiss Alps & MeteoSwiss & 184 \\
& IMIS & 178 \\
\hline \multirow{2}{*}{ Qilian Mountains } & HIWATER & 30 \\
& TPED & 3 \\
\hline
\end{tabular}

Chen et al., 2014). In this study, $2 \mathrm{~m}$ temperature and air temperatures of the lowermost 16 pressure levels covering $1000-500 \mathrm{mb}$ (with respect to an elevation range of $\sim 100$ $6000 \mathrm{~m}$ a.s.l) are used as $T_{\mathrm{sa}}^{\mathrm{c}}$ and $T_{\mathrm{pl}}^{\mathrm{c}}$ (see Appendix A for subscript/superscript conventions).

\subsection{Observations and quality control}

The observational mean daily air temperatures $\left(T_{\mathrm{obs}}\right)$ from the Swiss Alps and the Qilian Mountains are used for deriving model parameters and for evaluating results (Table 1, Fig. 1). Observation datasets from the Swiss Alps were obtained from the MeteoSwiss automatic monitoring network (184 stations) and from the Inter-cantonal Measurement and Information System (IMIS) at the WSL Institute for Snow and Avalanche Research SLF (178 stations). In the Qilian Mountains, there are 30 stations from the Heihe Watershed Allied Telemetry Experimental Research (HIWATER) and 3 stations from the Third Pole Environment Database (TPED) (Li et al., 2013). Temperatures are observed by automatic meteorological stations using intervals from 10 to $30 \mathrm{~min}$. The temperature from MeteoSwiss is observed using the Thygan instrument which has an accuracy of $\pm 0.01^{\circ} \mathrm{C}$, and temperatures from IMIS are measured by several different sensors (including Rotronic MP100H, Rotronic MP102H/HC2, Rotronic MP103A and Campbell Scientific CS215), with sensor accuracies ranging from \pm 0.1 to $\pm 0.9^{\circ} \mathrm{C}$. In the Qilian Mountains, temperature sensors HMP155 with a typical accuracy of $\pm 0.2^{\circ} \mathrm{C}$ are used. The 395 stations used cover an elevation range of $\sim 250-4150 \mathrm{~m}$ as well as different topographic positions including peaks, slopes, plains and deep valleys (Fig. 2a).

All temperature observations were filtered using a threshold (plausible values from -60 to $60^{\circ} \mathrm{C}$ ), and the outliers of temperature time series were removed by visual check. Time offsets between observations and ERA-Interim are avoided by conducting all analyses in UTC time. When using mean daily temperature, days with missing data were removed before further analysis. Though there are in total 395 stations used here, not all of them are available in a single year (Fig. 2b). In total, there are $\sim 2.5 \times 10^{6}$ observations of mean daily temperature in or after 1980 used here. 


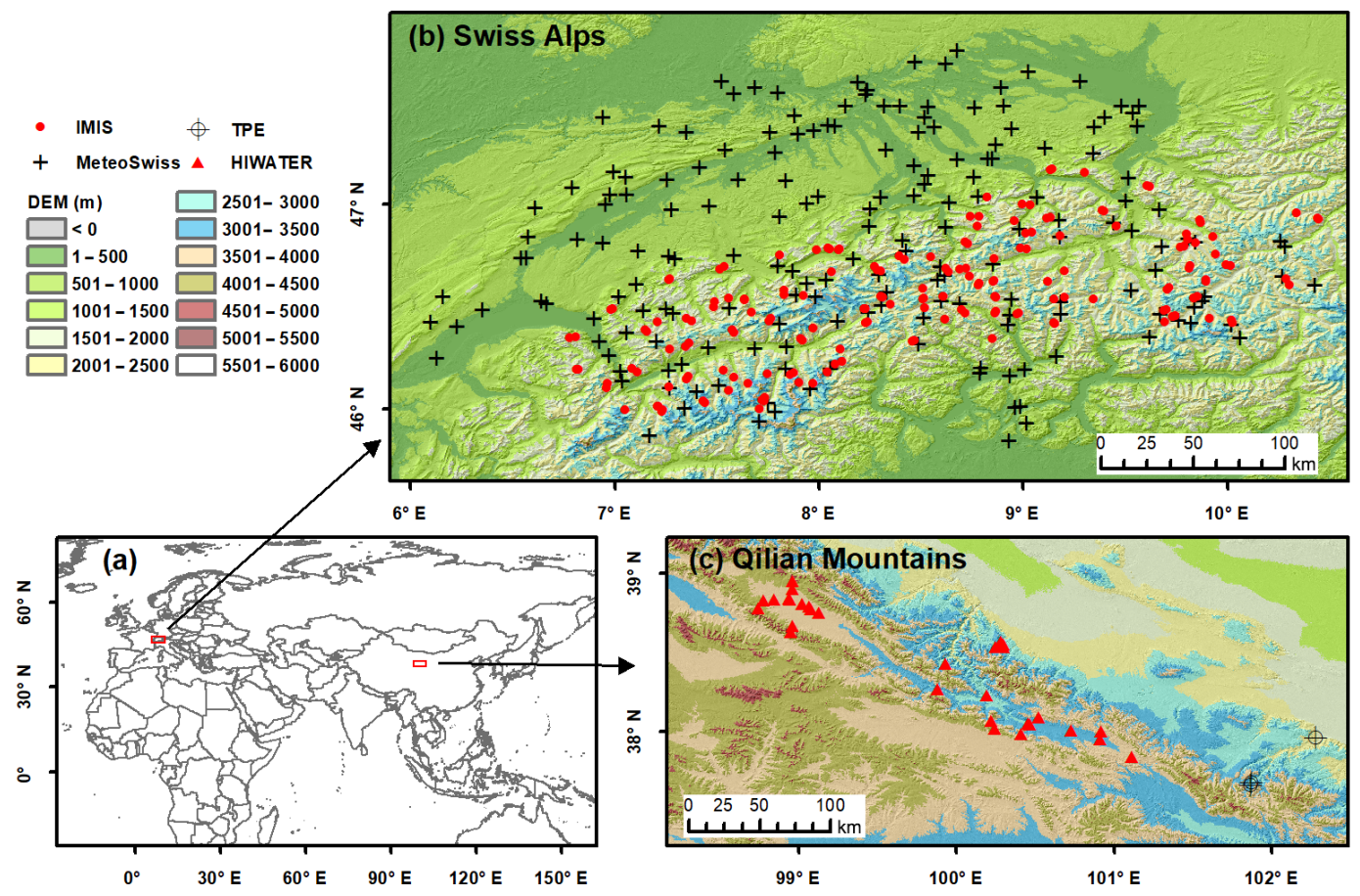

Figure 1. Location of experimental region (a): observation stations in the Swiss Alps (b) and the Qilian Mountains (c).
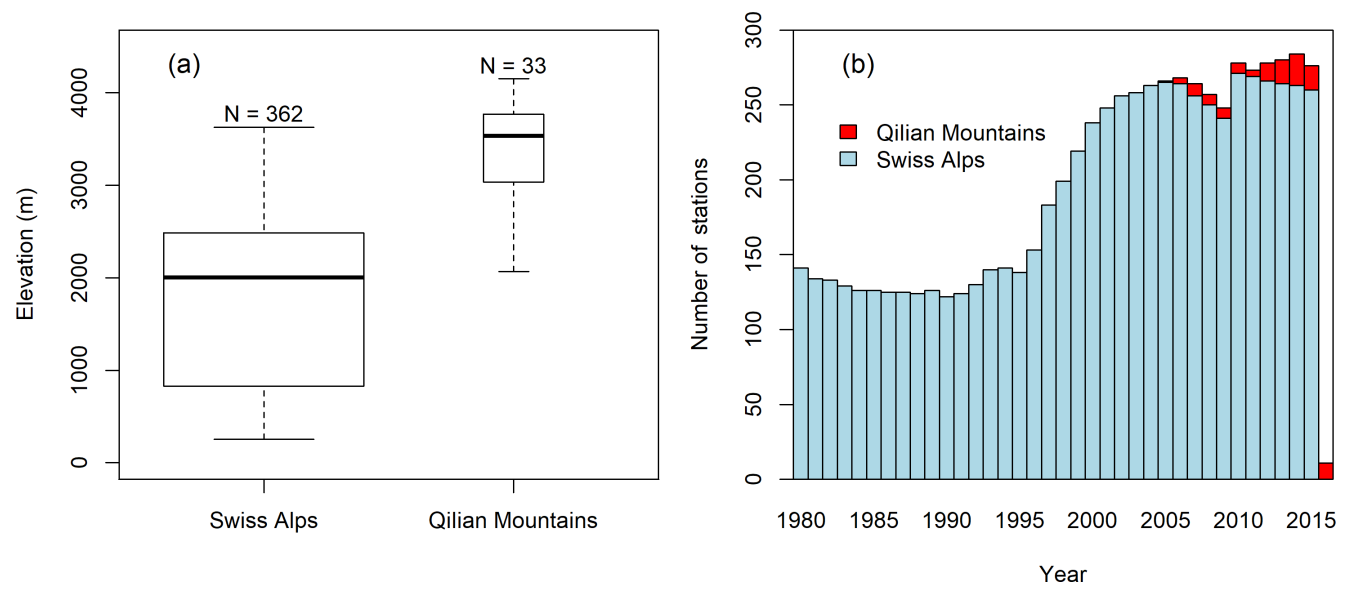

Figure 2. Elevation distribution of observation station (a) and number of observation stations $(N)$ used in different years (b).

\subsection{DEM}

The fine-scale topography was represented using a DEM with a resolution of $3 \operatorname{arcsec}(\sim 90 \mathrm{~m})$. To avoid the noise in the original dataset, the DEM used in this study was aggregated from the original Global Digital Elevation Model version 2 (GDEM2) with a grid spacing of 1 arcsec (Tachikawa et al., 2011; Meyer et al., 2011) to a spacing of $3 \operatorname{arcsec}$ by averaging (Fig. B1 in Appendix B).

\section{Methods}

Figure 3 shows a flowchart (a) and schematic illustration (b) of REDCAPP. The main steps can be summarized as (1) obtaining $T_{\mathrm{sa}}$ and interpolating $T_{\mathrm{pl}}^{\mathrm{c}}$ and $T_{\mathrm{pl}}^{\mathrm{f}}$ from the pressurelevel data (described in Sect. 4.1); (2) deriving $\Delta T^{\mathrm{c}}=$ $T_{\mathrm{sa}}-T_{\mathrm{pl}}^{\mathrm{c}}$ (described in Sect. 4.2); (3) estimating LSCF and hence $\Delta T^{\mathrm{f}}$ from the fine-scale DEM (described in Sect. 4.2); (4) obtaining fine-scale $T$ by adding $\Delta T^{\mathrm{f}}$ to $T_{\mathrm{pl}}^{\mathrm{f}}$. 

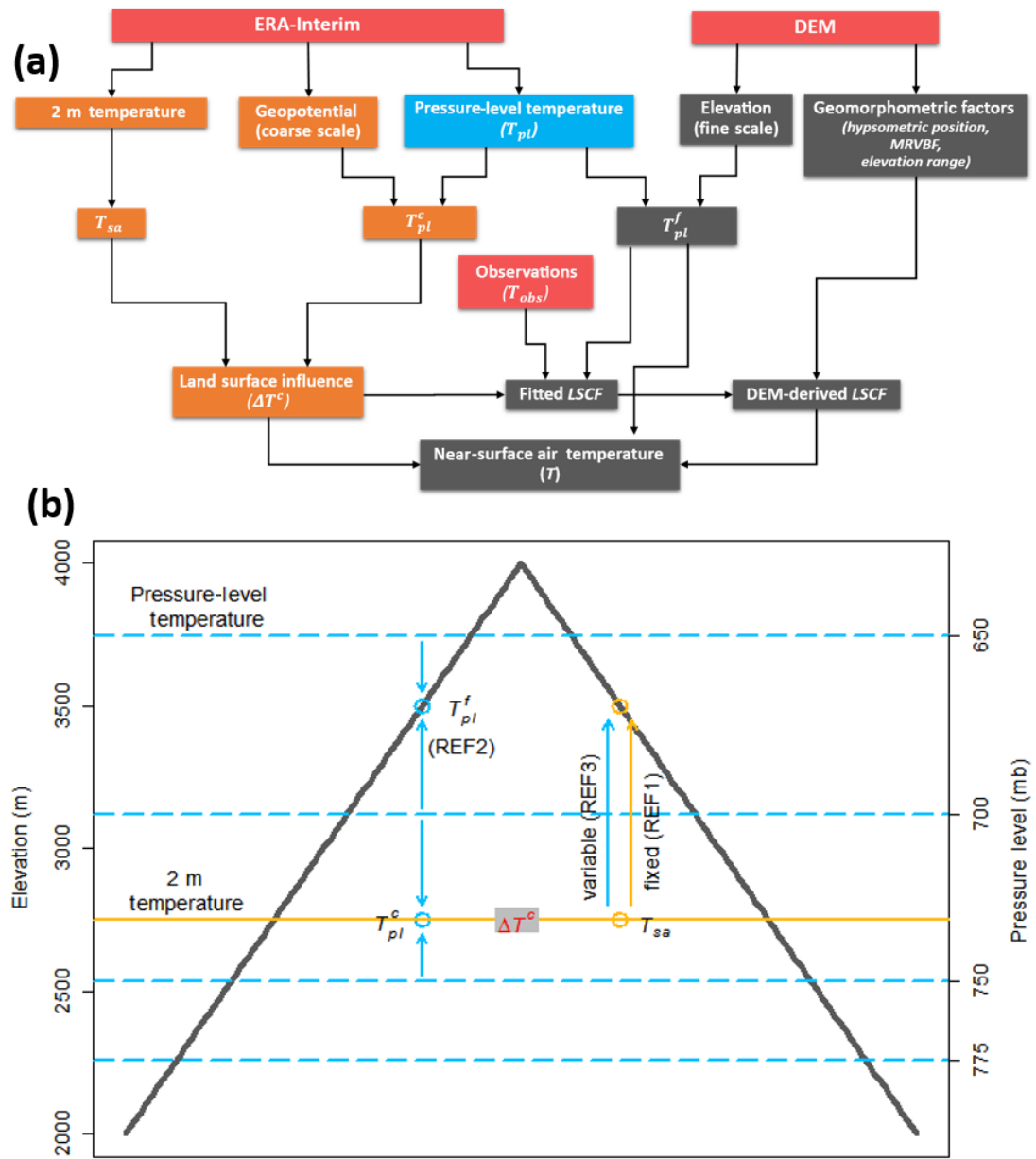

Figure 3. Model flow chart (a) and schematic illustration of interpolations and reference methods (b). Red squares denote input datasets. Variables at the elevation of coarse-scale topography are marked in yellow while the elevation of fine-scale topography is shown in grey. $T_{\mathrm{pl}}$ in blue could be at both the coarse and fine scales of elevation. Blue arrows and points are variable lapse rates and temperatures derived from $T_{\mathrm{pl}}$, while the yellow point is temperature derived from $T_{\mathrm{sa}}$, and the yellow arrow is the fixed lapse rate of $-6.5^{\circ} \mathrm{C} \mathrm{km}{ }^{-1}$. Detailed symbol and variable names can be found in Appendix A. The schematic illustration is revised from Fiddes and Gruber (2014).

The fundamental of REDCAPP is coupling the $\Delta T$ to the $T_{\mathrm{pl}}$ at each site and could be given by

$T=T_{\mathrm{pl}}+\Delta T$,

where $T_{\mathrm{pl}}$ is the air temperature of pressure level from ERAInterim, and $\Delta T$ is the influence of land surface. In response to the required fine scale of $T$, Eq. (1) could be changed to

$T=T_{\mathrm{pl}}^{\mathrm{f}}+\Delta T^{\mathrm{f}}$,

where $T_{\mathrm{pl}}^{\mathrm{f}}$ and $\Delta T^{\mathrm{f}}$ is the $T_{\mathrm{pl}}$ and $\Delta T$ at the elevation of finescale topography.

\subsection{Interpolation of air temperature}

By following Fiddes and Gruber (2014), $T_{\mathrm{pl}}^{\mathrm{f}}$ and $T_{\mathrm{pl}}^{\mathrm{c}}$ at a given site are obtained by 3-D interpolation of $T_{\mathrm{pl}}$. This is achieved in two steps: (1) 2-D interpolation: deriving the elevation of each pressure level by normalizing geopotential height (Eq. 3) and then conducting horizontal 2-D interpolation of temperature and elevation for each pressure level; (2) 1-D interpolation: vertically interpolating $T_{\mathrm{pl}}$ at different heights over one location to the required elevation.

Elevation $=\frac{\phi}{g_{0}}$

where $\phi$ is the geopotential height and $g_{0}$ is the acceleration due to gravity of $9.80665 \mathrm{~m} \mathrm{~s}^{-2}$. The geopotential and $T_{\mathrm{pl}}$ are extrapolated in the area where the pressure is greater than that of lowest level of ERA-Interim $(\sim 1000 \mathrm{mb})$ by using values of the lowest two pressure levels. The coarse-scale topography and $T_{\mathrm{sa}}$ are bilinearly interpolated to the resolution of the fine-scale grid in order to avoid blocky artifacts introduced by sudden changes of $\Delta T$ at the boundary of ERA-Interim cells. 


\subsection{Land-surface correction factor}

The land-surface effect $\Delta T^{\mathrm{c}}$ on simulated near-surface air temperature is given by

$\Delta T^{\mathrm{c}}=T_{\mathrm{sa}}-T_{\mathrm{pl}}^{\mathrm{c}}$.

LSCF is introduced here as a scale factor to obtain $\Delta T^{\mathrm{f}}$ from $\Delta T^{\mathrm{c}}$. Therefore, Eq. (2) becomes

$T^{\mathrm{f}}=T_{\mathrm{pl}}^{\mathrm{f}}+\mathrm{LSCF} \cdot \Delta T^{\mathrm{c}}$,

where LSCF describes the effect of fine-scale topography on the relative magnitude of land-surface effects. It is parameterized as

$\mathrm{LSCF}=\alpha \cdot h+\beta \cdot v$

where $\alpha, \beta$ are positive numbers obtained from fitting with observations, and $h$ and $v[0,1]$ are factors derived heuristically from geomorphology on the fine-scale topography. The lowercase variables of $h$ and $v$ are derived by scaling hypsometric position $(H)$ and the degree of valleyness $(V)$ with a scaling factor

$S=\exp \left(\frac{-R}{\gamma}\right)$

where $R$ is the elevation range in a prescribed neighborhood of analysis and $\gamma$ is a fitting parameter. This scaling reflects the fact that stronger topographic effects on air temperature are to be expected with increasing elevation range. $S$ is equal to 1 for $R=0$ and 0 for very large $R$ values (Fig. 4a).

Hypsometric position $H$, the basis for $h$, is the ratio of the number of cells with higher elevation than a given site to the total number of cells in a prescribed neighborhood of analysis. It ranges from 1 (deepest valley) to 0 (highest peak). The prescribed neighborhood of analysis for both $H$ and $R$ is taken as $30 \mathrm{~km} \times 30 \mathrm{~km}$. For computational efficiency, $H$ is derived based on a DEM aggregated to 15 arcsec $(\sim 450 \mathrm{~m})$ by averaging and the results are nearly identical (Appendix B1). Then, $H$ is scaled to obtain

$h=H \cdot(1-S)+S$.

The lowest point in the landscape thus always receives a weight of 1 in $h$ (Fig. 4b).

The factor $v$ is based on scaling a measure of the degree of valleyness $[0,1]$ :

$v=V \cdot(1-S)$,

where $v$ becomes larger with increasing elevation range (Fig. 4c) and $V$ is described by the normalized multiresolution valley bottom flatness (MRVBF) index (Gallant and Dowling, 2003):

$V=\frac{\mathrm{MRVBF}}{\mathrm{MRVBF}_{\max }}$,
Table 2. Summary of reference methods.

\begin{tabular}{lllr}
\hline $\begin{array}{l}\text { Reference } \\
\text { method }\end{array}$ & $\begin{array}{l}\text { Lapse } \\
\text { rate }\end{array}$ & $\begin{array}{l}\text { Base } \\
\text { temperature }\end{array}$ & LSCF \\
\hline REF1 & $-6.5^{\circ} \mathrm{C} \mathrm{km}^{-1}$ (fixed) & $T_{\mathrm{sa}}$ & 1 \\
REF2 & $T_{\mathrm{pl}}$-based (variable) & $T_{\mathrm{pl}}$ & 0 \\
REF3 & $T_{\mathrm{pl}}$-based (variable) & $T_{\mathrm{sa}}$ & 1 \\
\hline
\end{tabular}

REF2 is from Fiddes and Gruber (2014), while REF3 is from Gao et al. (2012)

where MRVBF identifies valley bottoms occurring at a range of scales (Gallant and Dowling, 2003), and $\mathrm{MRVBF}_{\max }$ is a constant value of 8 based on the maximum MRVBF. The original slope threshold used to scale flatness of topography is increased to $50 \%$ in this study, so that the MRVBF is smoother (Appendix B2).

The main parameters for REDCAPP, denoted by the greek letters $\alpha, \beta$ and $\gamma$, are derived from fitting with observational data. For this, values for LSCF were fitted where observations exist. Then, model parameters for predicting these LSCFs were derived using global optimization function "differential_evolution" of the Python package SciPy (Storn and Price, 1997).

\subsection{Reference methods}

Three reference methods using different sources of air temperature and lapse rate are used to compare with the new downscaling scheme (Table 2, Fig. 3). $T_{\text {sa }}$ is extrapolated by using a fixed lapse rate of $-6.5^{\circ} \mathrm{C} \mathrm{km}^{-1}$ (REF1) and by using variable lapse rate modeled from $T_{\mathrm{pl}}$ (REF3) (Giorgi et al., 2003; Gao et al., 2012). Linearly interpolated $T_{\mathrm{pl}}$ is referenced as REF2 (Fiddes and Gruber, 2014; Gupta and Tarboton, 2016). Since only the upper-air temperatures are used in REF2, this is equivalent to setting LSCF uniformly to 0 (no land-surface influence), while LSCF is uniformly considered to be 1 in REF1 and REF3, which use $T_{\text {sa }}$ as their base temperature. To evaluate the performance of REDCAPP against the three reference methods, the coefficient of determination $\left(R^{2}\right)$, root mean squared error (RMSE) and mean bias (BIAS) were computed here.

$\begin{aligned} \mathrm{RMSE} & =\sqrt{\frac{\sum_{t=1}^{N}\left(\mathrm{OBS}_{t}-\mathrm{MOD}_{t}\right)^{2}}{N}} \\ \mathrm{BIAS} & =\frac{1}{N} \sum_{t=1}^{N}\left(\mathrm{MOD}_{t}-\mathrm{OBS}_{t}\right)\end{aligned}$

\section{Results}

In this section, results are presented in the order of research questions outlined in the introduction. We first investigate 

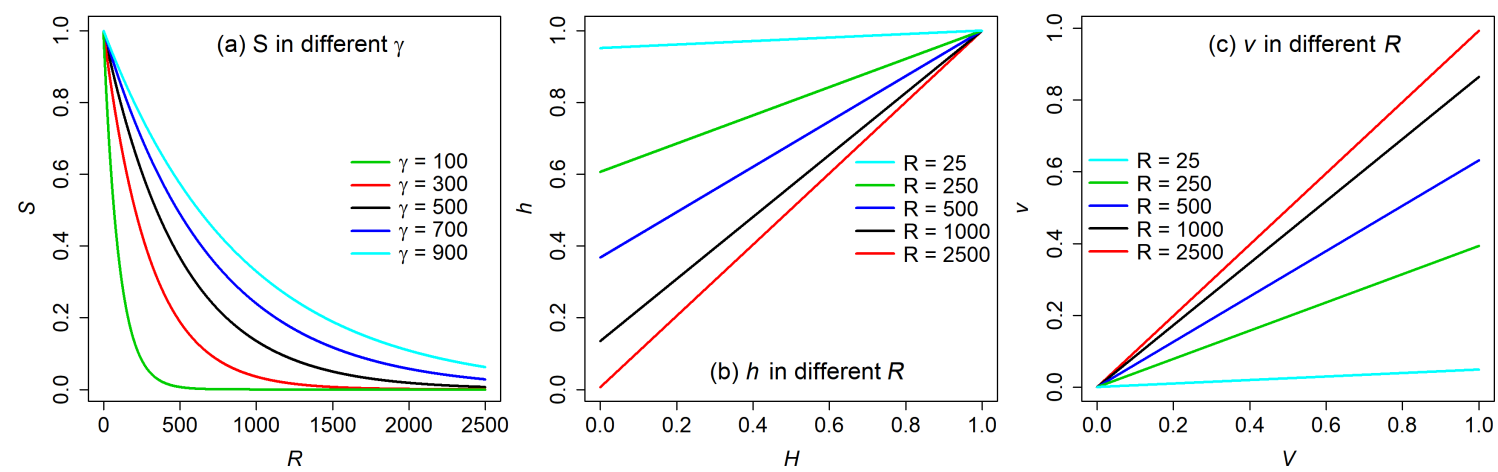

Figure 4. (a) Scale factor $(S)$ decreases with increasing elevation range $(R)$ by using different $\gamma$ values. Fraction influence of surface effect on $T(h)$ increases with hypsometric position $(H)$ and strength of CAP $(v)$ increases with the normalized multiresolution valley bottom flatness $(V), \gamma$ is 500 in panels $(\mathbf{b}, \mathbf{c})$. The lowest point in the landscape always receives a weight of 1 in $h$ and a weight of 0 in $v$.
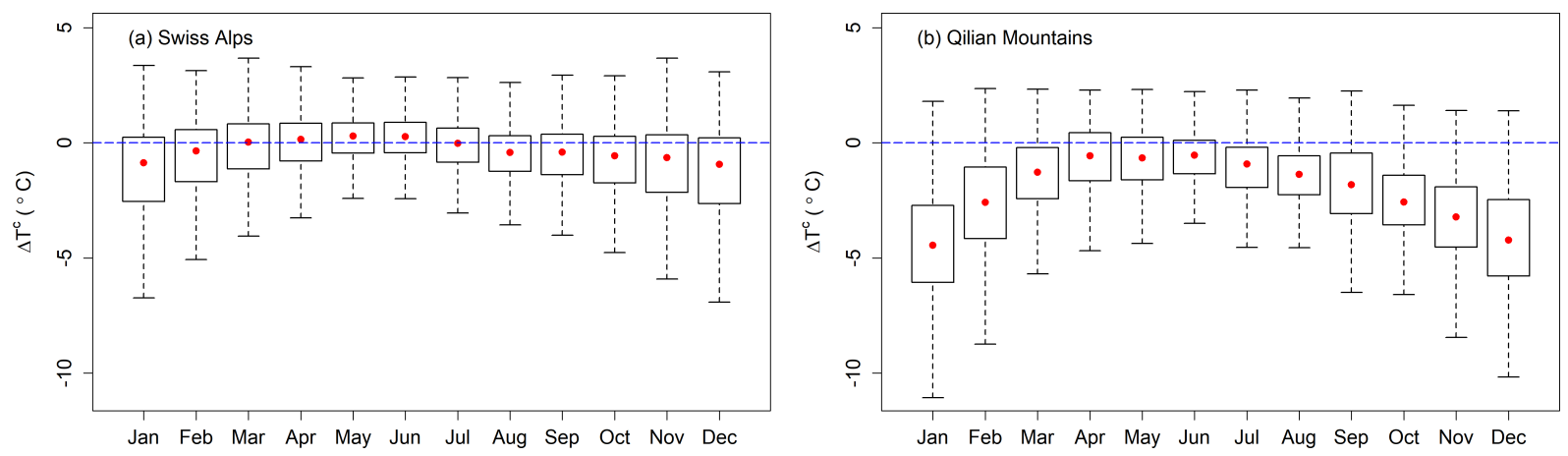

Figure 5. Seasonal changes shown as monthly distributions of average daily $\Delta T^{\mathrm{c}}$ derived from ERA-Interim for the locations of all stations. Red dots are median values.

$\Delta T$ and whether it can be used for parameterizing cold air pooling and surface effects. Then, we investigate LSCF and its estimation based on a fine-scale DEM. Finally, the performance of REDCAPP is evaluated.

\subsection{Properties of $\Delta T$}

Figure 5 presents seasonal variations of daily $\Delta T^{\mathrm{c}}$. In general, $\Delta T^{\mathrm{c}}$ is close to $0^{\circ} \mathrm{C}$ in warm seasons with the median value sightly above $0^{\circ} \mathrm{C}$ in the Swiss Alps from March to June and greater than $-0.8^{\circ} \mathrm{C}$ in the Qilian Mountains from April to June. In winter, lower median $\Delta T^{\mathrm{c}}$ values are found in both the Swiss Alps and the Qilian Mountains. Furthermore, a larger range of $\Delta T^{\mathrm{c}}$ in winter is caused by lower minima of $\Delta T^{\mathrm{c}}$, likely related to radiative cooling.

Figure 6 shows one year of daily $\Delta T^{\mathrm{c}}$ as well as $T$ derived from observations and downscaling at selected sites. The downscaled series are either ignoring $\Delta T^{\mathrm{c}}$ (REF2) or adding it uniformly (REF3) to all stations. Daily $\Delta T^{\mathrm{c}}$ shows a similar pattern to Fig. 5. At the mountain sites (COV, BEV1, DDS; see Table 3), $T_{\mathrm{pl}}^{\mathrm{f}}$ describes $T_{\mathrm{obs}}$ well without accounting for $\Delta T^{\mathrm{c}}(\mathrm{REF} 2)$, and the RMSEs were less than $1.4^{\circ} \mathrm{C}$ (Table 3). By contrast, REF2 does not describe $T_{\text {obs }}$ well at valley locations, especially in winter, and RMSEs are markedly higher. In comparison, the results of REF3, through adding $\Delta T^{\mathrm{c}}$ to $T_{\mathrm{pl}}^{\mathrm{f}}$, follow $T_{\mathrm{obs}}$ better at valley sites (SAM, SIA, EBO) and worse at mountain sites. Although REF3 improves predictions in deep valleys (e.g., SAM), results in winter are still higher than the observations because winter inversions here are stronger than predicted by $\Delta T^{\mathrm{c}}$.

These results highlight the spatial and temporal variability of land-surface effects on $T$. As the full incorporation of $\Delta T^{\mathrm{C}}$ in downscaling improves predictions in valley locations and degrades them in mountain sites, a spatially variable LSCF appears to be a promising means for better predicting landsurface effects on $T$ at the fine scale.

\subsection{Land-surface correction factor}

At the example of selected stations (Table 3), Fig. 7 shows that $\Delta T^{\mathrm{c}}$ correlates with the difference of observed temperature and a prediction involving pressure levels only ( $T_{\mathrm{obs}}$ $\left.T_{\mathrm{pl}}^{\mathrm{f}}\right)$. Therefore, $\Delta T^{\mathrm{c}}$ can be used to correct for some of the difference found between them. The fitted LSCF is related to the topography and increases from near 0 at mountain peaks to almost 2 in deep valleys. This indicates the possibility of predicting LSCF based on a DEM. Furthermore, fitted 

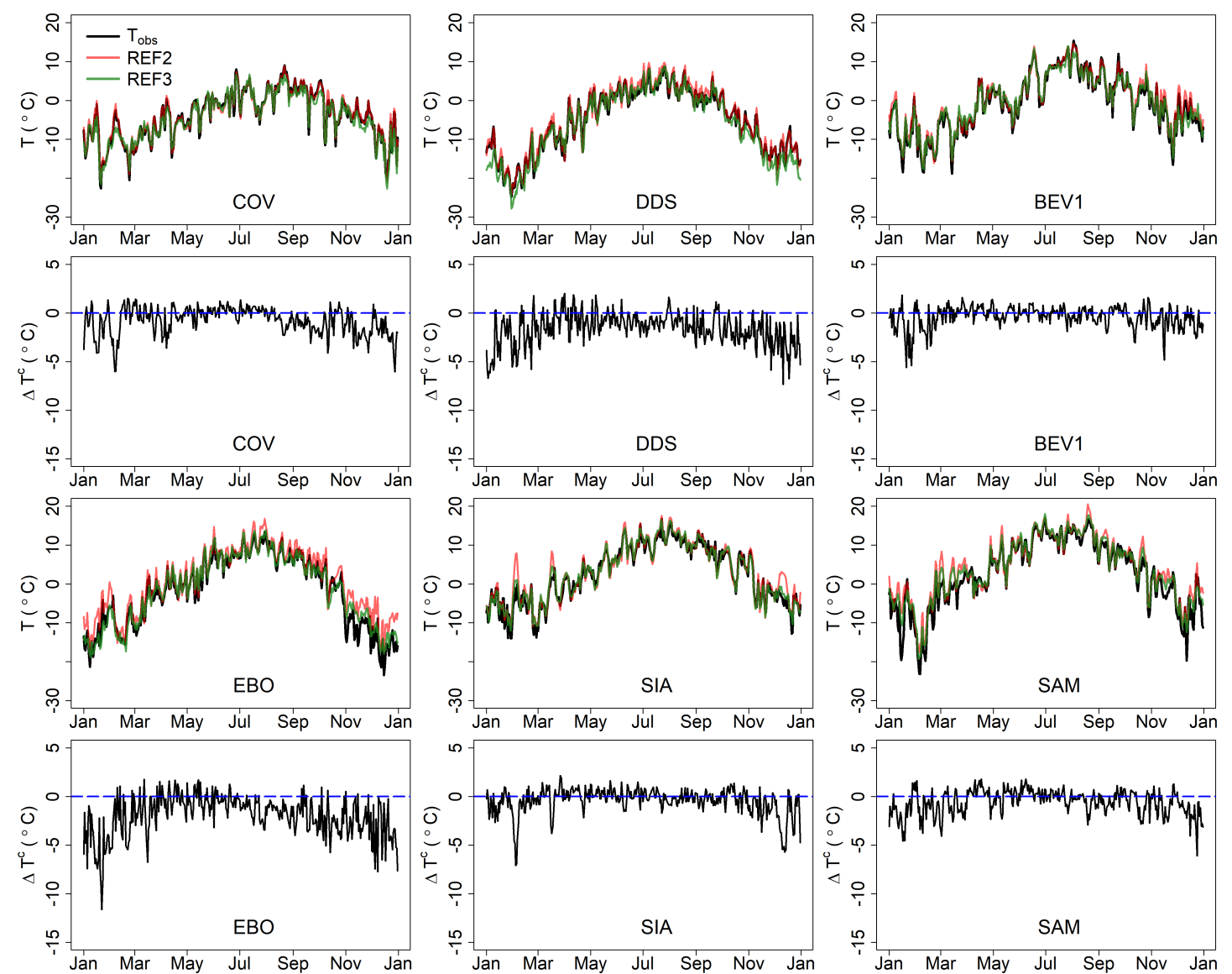

Figure 6. Detailed time series of $\Delta T^{\mathrm{c}}, T_{\mathrm{obs}}, \mathrm{REF} 2$ and REF3 at the selected stations from different geomorphometric positions.

Table 3. Comparison of observations against reference methods of REF2 and REF3.

\begin{tabular}{|c|c|c|c|c|c|c|c|c|c|}
\hline \multirow[b]{2}{*}{ Station } & \multicolumn{4}{|c|}{ Location } & \multirow[b]{2}{*}{ Observation period } & \multicolumn{2}{|c|}{ REF2 } & \multicolumn{2}{|c|}{ REF3 } \\
\hline & Lat. $\left(^{\circ}\right)$ & Long. $\left(^{\circ}\right)$ & Elev. (m) & Topography & & RMSE & BIAS & RMSE & BIAS \\
\hline $\mathrm{COV}$ & 46.4180 & 9.8212 & 3351 & Peak & Jan 1998-Dec 2015 & 1.01 & 0.24 & 1.63 & -0.41 \\
\hline DDS & 38.0142 & 100.2421 & 4147 & Peak & Oct 2007-Oct 2009 & 1.34 & 0.56 & 2.38 & -1.05 \\
\hline BEV1 & 46.5487 & 9.8538 & 2490 & Peak & Sep 1997-Dec 2015 & 1.22 & 0.54 & 1.41 & 0.04 \\
\hline EBO & 37.9492 & 100.9151 & 3294 & Slope & Jun 2013-Dec 2014 & 3.31 & 2.41 & 1.87 & 0.43 \\
\hline SIA & 46.4323 & 9.7623 & 1853 & Valley & Jan 1980-Dec 2015 & 2.44 & 1.14 & 1.65 & 0.50 \\
\hline SAM & 46.5263 & 9.8789 & 1756 & Valley & Jan 1980-Dec 2015 & 3.85 & 1.95 & 2.81 & 1.39 \\
\hline
\end{tabular}

LSCFs greater than 0 hint at the possibility of representing CAPs by using a LSCF and $\Delta T^{\mathrm{c}}$.

To assess the performance of DEM-derived LSCF (based on Eq. 5), we conducted a 10-fold cross validation separately for the Swiss Alps and the Qilian Mountains (Fig. 8). Each time, $\sim 90 \%$ of the observations are randomly selected for deriving model parameters and the remaining $10 \%$ are used for evaluation. Results show an RMSE of 0.29 and 0.26 , a BIAS of 0 and 0.03 , as well as an $R^{2}$ of 0.69 and 0.60 in the Swiss Alps and the Qilian Mountains. These results indicate that LSCF can be estimated from a DEM based on geomorphometry and that results will be useful in improving downscaling.

Model parameters for estimating LSCF were derived by using all stations but separately for the Swiss Alps and the Qilian Mountains (Table 4). Figure 9 shows the spatial fields of topographic factors in selected area based on the modeled factors. Hypsometric position and normalized MRVBF, and therefore LSCF, vary strongly with topography. In the test area shown, LSCF ranges from near 0 on mountain peaks to about 1.67 in deep valleys. 

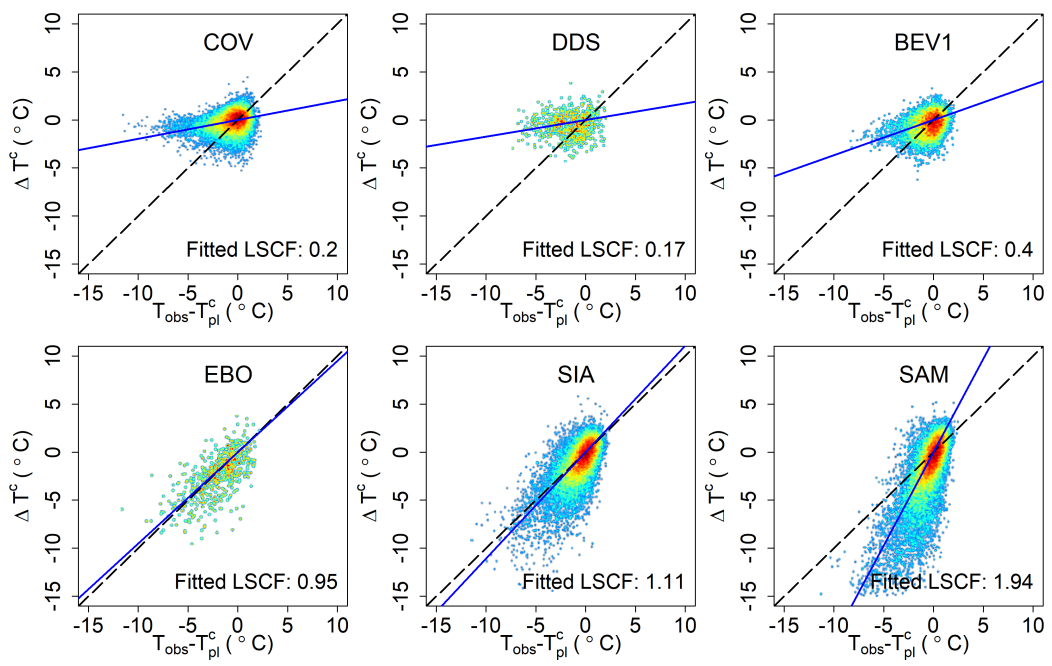

Figure 7. Difference of observed temperature and a prediction involving pressure levels $\left(T_{\mathrm{obs}}-T_{\mathrm{pl}}^{\mathrm{f}}\right)$ against $\Delta T^{\mathrm{c}}$. The representation is a smoothed color density of a scatter plot to make a quantity of points visual. The lines are results of LSCF $\times \Delta T^{\mathrm{c}}$ by using LSCF of 1 (black dash) and best-fitted LSCF (blue solid) at the selected stations. The time periods of the stations are presented in Table 3.

Table 4. Summary of model parameters for estimating LSCF from DEMs.

\begin{tabular}{lrrr|rrr}
\hline Area & \multicolumn{3}{c|}{ Model parameters } & \multicolumn{3}{c}{ Evaluation } \\
\cline { 2 - 7 } & $\alpha$ & $\beta$ & $\gamma$ & $R^{2}$ & RMSE & BIAS \\
\hline Swiss Alps & $0.61 \pm 0.03$ & $1.56 \pm 0.04$ & $465 \pm 50$ & 0.69 & 0.29 & 0.00 \\
Qilian Mountains & $0.90 \pm 0.08$ & $0.34 \pm 0.11$ & $138 \pm 20$ & 0.68 & 0.26 & 0.03 \\
\hline
\end{tabular}

The values after \pm are standard deviations derived from 10-fold cross validation.

\subsection{Performance of REDCAPP}

\subsubsection{Comparison with station data}

Figure 10 shows plots of $T_{\mathrm{obs}}$ against results of REF1, REF2, REF3 and REDCAPP (MOD), and indicates that REDCAPP improves the prediction of $T$ over reference methods. The downscaled results achieve better measures of agreements or reduce deviance by comparing the references methods. This is because REF3 resulted in air temperatures being too low at high elevation, while the influence of CAP was underestimated in valleys by applying a fixed LSCF of 1 to the entire area. As a result, the BIAS of REF3 is very close to 0 due to differing biases canceling out each other.

Figure 11 shows the seasonal deviance of downscaled daily results (MOD-OBS) for different methods. Similar to the detailed comparison of typical stations showed in Fig. 6, REF2 captures temperatures in summer well but has a warm bias in winter. By contrast, REF1 predicts $T$ too low in winter. This is because the lapse rates are expected to increase due to the presence of CAPs. There is no obvious seasonal trend in the median deviation of REF3. However, the minimum of deviation is smaller than REF2 in winter. REDCAPP captures $T$ well in both winter and summer. The median de- viation for each month was within $\pm 0.50^{\circ} \mathrm{C}$ (from -0.06 to $0.48^{\circ} \mathrm{C}$ ) in the Swiss Alps and within $\pm 0.55^{\circ} \mathrm{C}$ (from -0.53 to $0.45^{\circ} \mathrm{C}$ ) in the Qilian Mountains.

Figure 12 shows the deviances of downscaled results by elevation. REF2 performs well at high-elevation areas, with the median deviance close to 0 , but has a warm bias with decreasing elevation. By contrast, REF1 and REF3 tend to have a cold bias at high elevation and often an increasing range of deviance with elevation. REDCAPP captures $T$ well across elevations. The median deviance was within \pm 0.70 (from -0.24 to 0.68$)^{\circ} \mathrm{C}$ in the Swiss Alps and within \pm 1.25 (from -0.76 to 1.22$)^{\circ} \mathrm{C}$ in the Qilian Mountains.

Figure 13 shows a comparison of REF2, REF3 and REDCAPP with time series at selected sites. Similar to the fitted LSCFs, DEM-derived LSCFs are spatially variable and increase from near 0 near mountain peaks to more than 1 in some slopes and deep valleys. REDCAPP improves the prediction of $T$ at all the topographic positions by comparing with reference methods. In summer, REDCAPP captures $T$ well, in winter, the BIAS is decreased through adding the influences of CAPs, especially by using the DEM-derived LSCF larger than 1. 

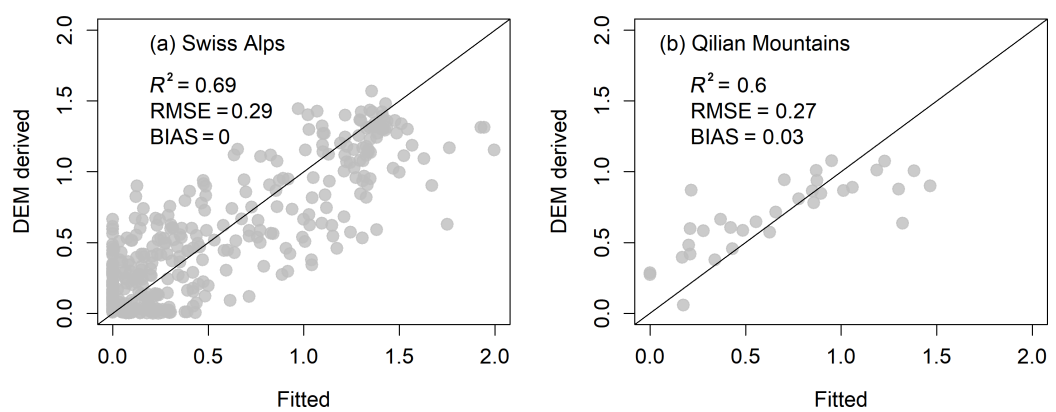

Figure 8. A 10-fold cross validation of DEM-derived LSCF against fitted values in the Swiss Alps (a) and the Qilian Mountains (b).
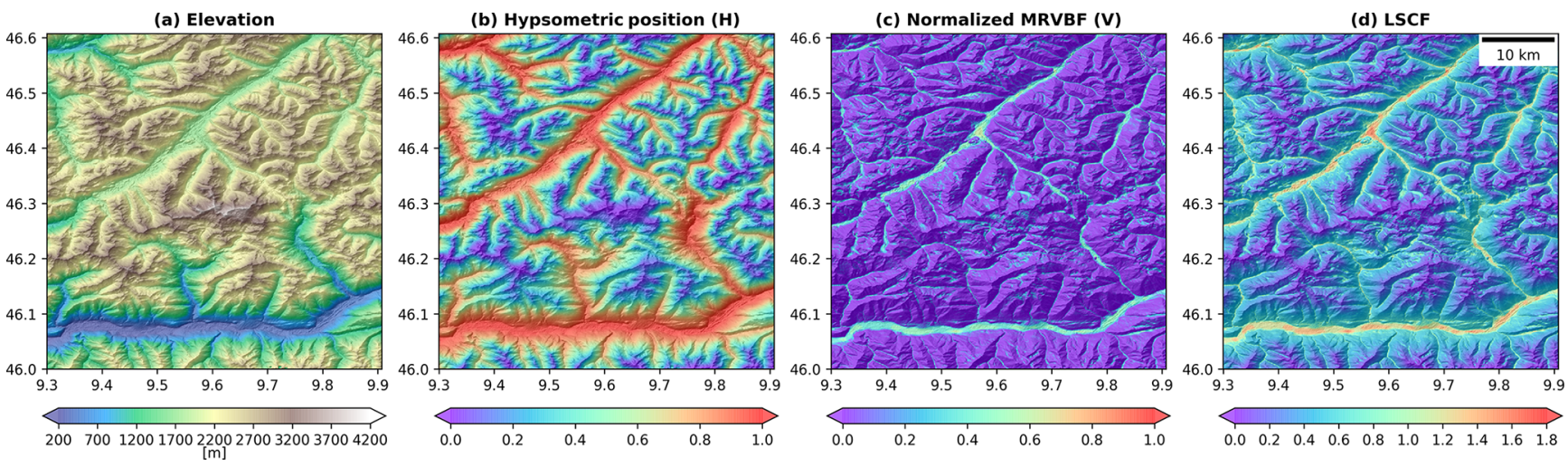

Figure 9. Spatial variation of elevation (a), hypsometric position (b), normalized MRVBF (c) and LSCF (d) in selected slope terrain.

\subsubsection{Spatial signature of REDCAPP}

Figure 14 shows the spatial variation of mean annual $\Delta T^{\mathrm{f}}$ for the year 2015. In valleys, downscaled $T$ can be up to $-2.1{ }^{\circ} \mathrm{C}$ lower than $T_{\mathrm{pl}}^{\mathrm{f}}$. With increasing elevation, the simulated landsurface effect decreased to almost $0{ }^{\circ} \mathrm{C}$. This gives a clear picture on the topography-related spatial variability of $\Delta T^{\mathrm{f}}$ and indicates REDCAPP can capture the variations well.

\section{Discussion}

In this section, we discuss advantages and limitations of the model and how it could be further refined in the future. We have demonstrated that information from coarse-scale models $\left(\Delta T^{\mathrm{c}}\right)$ can be used as a proxy of land-surface effects and, with a disaggregation factor (LSCF) estimated from a fine-scale DEM, can improve air temperature downscaling in mountains. At the same time, this finding needs to be put into perspective: a full simulation of the atmospheric physics and land surface at high resolution will likely outperform this parameterization but at a cost that is orders of magnitude higher (Fowler et al., 2007). Ultimately, the choice of method (or combination of several methods) depends on the problem at hand. It is likely that the parameterization put forward here can be further improved in its ability to predict fine-scale patterns and its suitability for transferring parameters between areas and thus the suitability for application in data-sparse regions. Nevertheless, REDCAPP and similar methods (Fiddes et al., 2015; Gupta and Tarboton, 2016) demonstrate that coarse-scale information on atmospheric variables can contribute to better prediction at finer scales without the need for increased resolution in the atmospheric model.

\subsection{Comparison with other downscaling techniques}

Though the upper-air temperatures $\left(T_{\mathrm{pl}}^{\mathrm{f}}\right.$ and $\left.T_{\mathrm{pl}}^{\mathrm{c}}\right)$ are obtained following Fiddes and Gruber (2014), disaggregating the difference of upper-air and near-surface temperatures as a proxy of surface effects $(\Delta T)$ makes REDCAPP a new method. Additionally, the $\Delta T$ in REDCAPP is adjusted to fine scale in response to the spatial heterogeneity of surface effect based on LSCF derived from DEM and observations, rather than ignored (REF2) or treated as spatially invariant (REF1 and REF3).

Besides the lapse-rate correction methods referenced in this study, many existing downscaling approaches for mountainous terrain focus on deriving fine-scale $T$ through interpolation (e.g., truncated Gaussian weighting filter, inverse distance weighting or kriging) of surrounding observations, and adjustments are then made based on fine-scale topography. The Parameter-elevation Regressions on Independent Slopes Model (PRISM) (Daly et al., 2000, 2002), for example, derives a weighing function to represent the relationship 

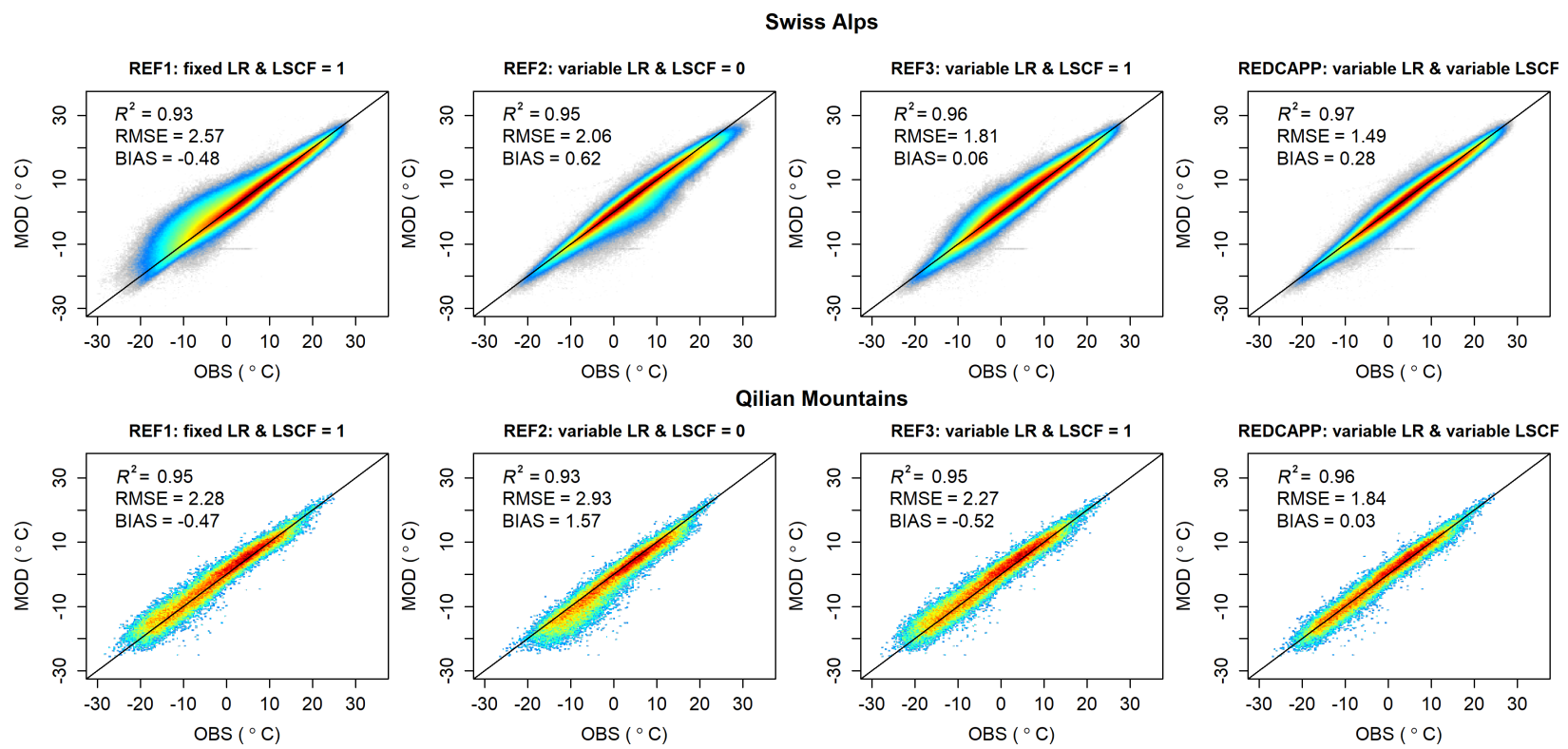

Figure 10. $T_{\text {obs }}(\mathrm{OBS}$ ) against results of REF1, REF2, REF3 and REDCAPP (MOD). LR in the subtitles indicates lapse rate.
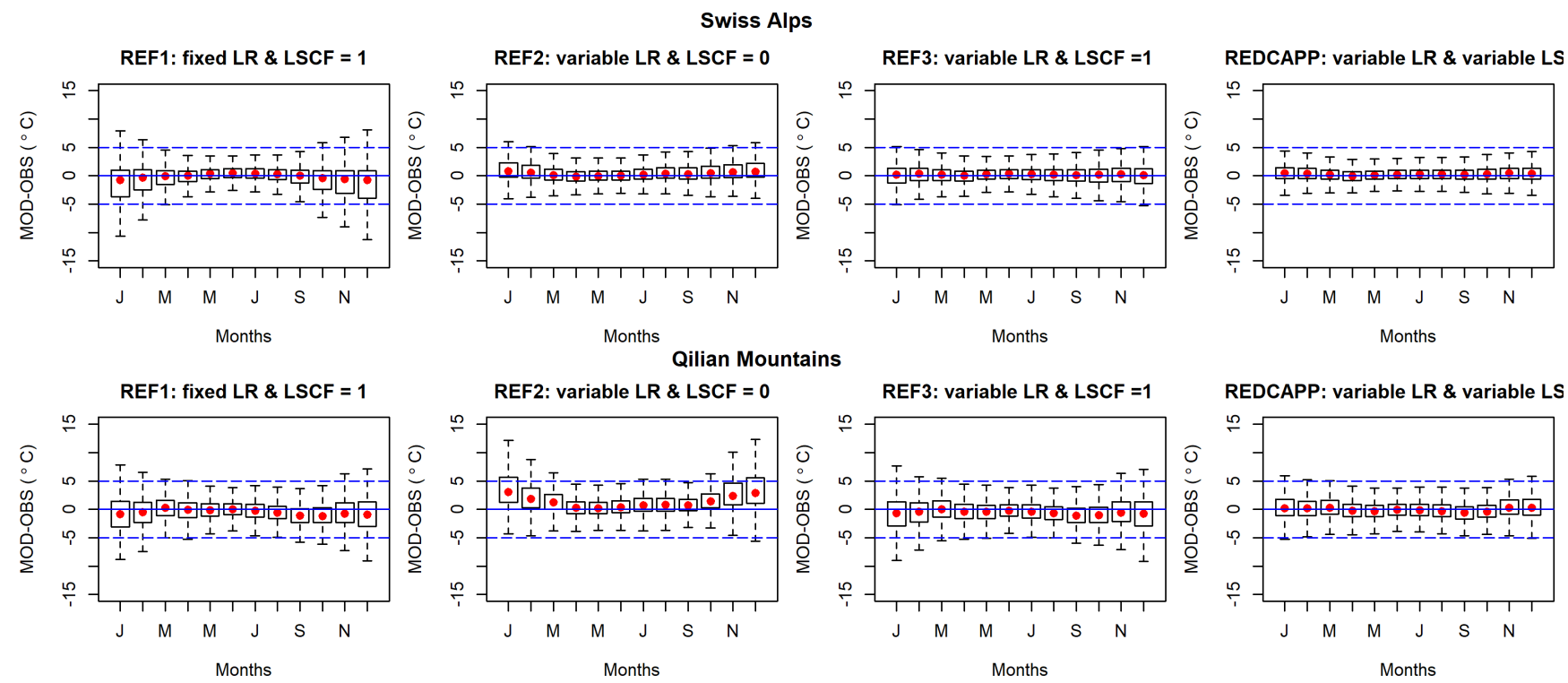

REDCAPP: variable LR \& variable LS

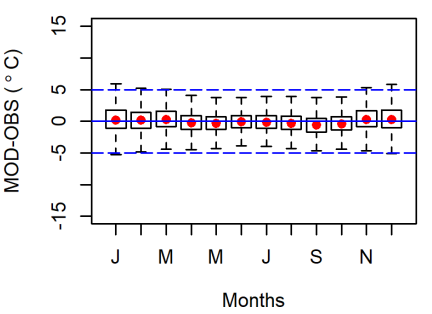

Figure 11. Seasonal deviance of downscaled daily results (MOD-OBS) for different methods. Red dots are median values.

of $T$ with geographic (e.g., slopes, coastal) and meteorological (e.g., atmosphere boundary layer) factors . Similarly, the approach by Thornton et al. (1997) calculates interpolation weights for the stations nearby and corrects the downscaled results based on an empirical relationship of $T$ to elevation, and Hijmans et al. (2005) conducted a second-order spline interpolation using latitude, longitude and elevation as independent variables. As observations are usually sparse in mountains, especially at higher elevation, these methods are expected to have significant uncertainty caused by inadequate sampling of elevation and hence lapse rate. In compar- ison, REDCAPP relies on reanalysis data for air temperature and uses station data only for calibration of the LSCF related to CAP. REDCAPP derives lapse rates from multiple layers of upper-air temperature encompassing the entire elevation range of study area. Thus, REDCAPP results are expected to be robust because both the $T_{\mathrm{sa}}$ and $T_{\mathrm{pl}}$ from reanalysis are used.

\subsection{Land-surface correction factor}

For simplicity, we model the influence of CAP and other land-surface effects on $T$ with one LSCF that varies spatially 

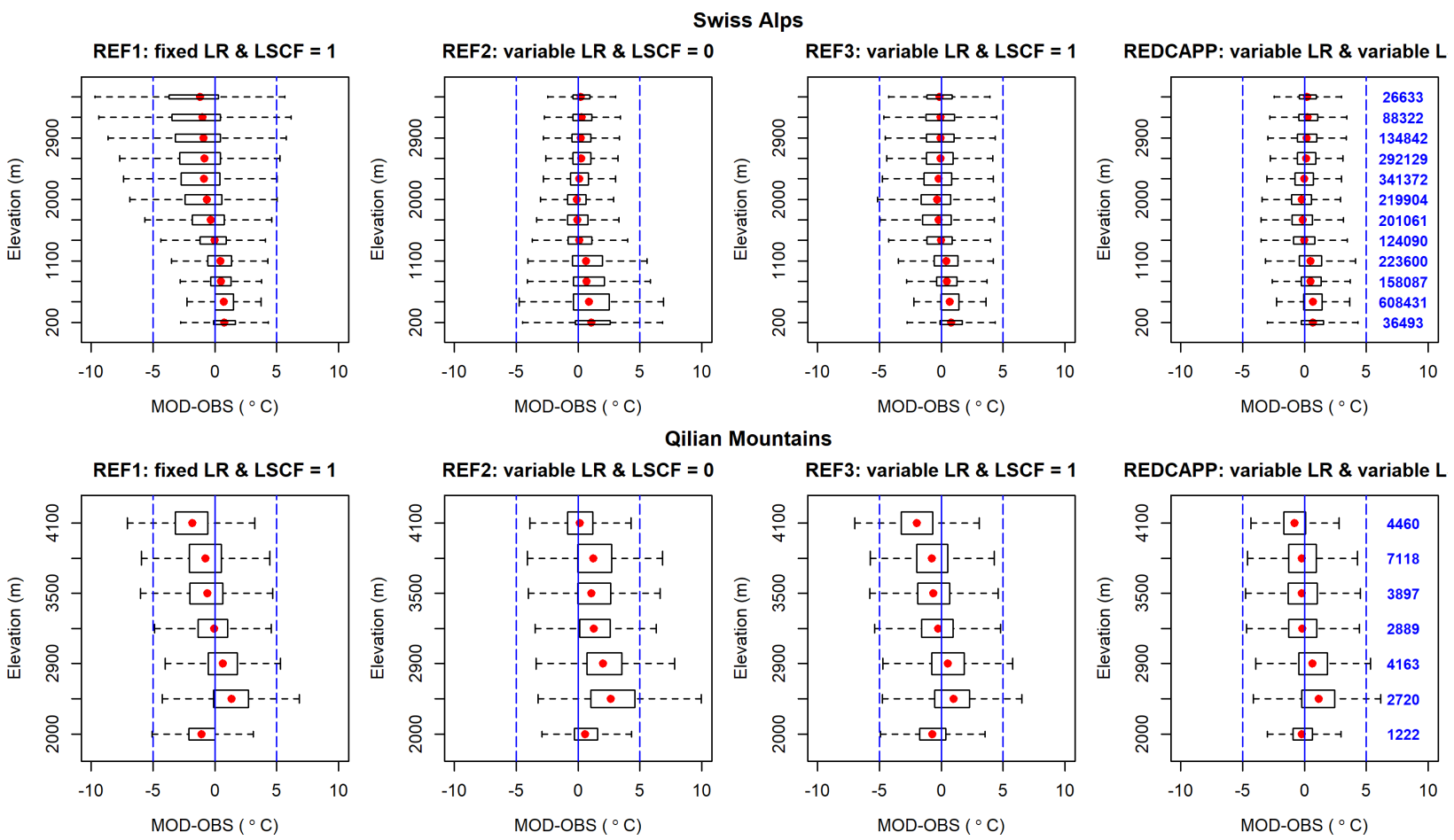

Figure 12. Deviances of downscaled results by elevations. The stations are grouped by elevation with an interval of $300 \mathrm{~m}$. Each box may contain multiple stations and the numbers of observation times (days) are given in blue on the right. Red dots are median values.

but is constant over time. This lumped nature of LSCF is imperfect because the presence of strong valley inversion in winter and their absence in the warm season would suggest a seasonally variable LSCF. In other words, LSCF is expected to be greater in winter than in summer as the fractional influence of CAP (the part of $\beta$ in Eq. 6) should be removed from LSCF. In REDCAPP, applying the same LSCF year-round to $\Delta T^{\mathrm{c}}$ will make downscaled $T$ higher in winter and lower in summer. A potential avenue for addressing this problem is simulating the likelihood for CAPs based on surface net radiation or Richardson number based on the reanalysis data.

\subsection{Transferability}

Based on the 10-fold cross validation, LSCF is modeled well in both the Swiss Alps and the Qilian Mountains. The resulting parameter values, however, are different (Table 4). The reasons for this can be speculated to include differences in topography (e.g., valley shape), the number and distribution of stations used, climate (continentality, effect of lumping two processes into one LSCF) or differences in land-surface characteristics (e.g., canopy and snow cover). The difference in estimated parameter values of LSCF limits the direct transferability of REDCAPP parameters from the mountains tested here to others, as it requires new calibration in other mountain regions. This is a significant drawback and we hope that over time, application in many mountain ranges will help to establish correlations of trusted parameter values with en- vironmental conditions. REDCAPP can be applied to other mountains once the parameters ( $\alpha, \beta$ and $\gamma$ in Eqs. 6 and 7) of LSCF are derived based on observations and a fine-scale DEM.

\subsection{Input data}

Although we only apply and test our method with ERAInterim here, it can be used with other reanalyses such as CFSR, NCEP, MERRA or 20CRV2. Besides global reanalyses, regional high-resolution assimilations produced by RCMs (e.g., E-OBS, Chinese Academy of Sciences forcing data, ASR) (Chen et al., 2011), and upper-air temperature reanalyses (e.g., ASR) may be suitable alternatives in some regions. These regional assimilations often capture surface air temperature better by assimilating more observations and by using finer grids than global reanalyses. Since upper-air temperature and $\Delta T$ are treated separately in REDCAPP, they can also be derived from different data sources.

\subsection{Future development}

After lapse-rate correction, the key issue for $T$ downscaling (not only in mountain regions) is resolving variations caused by the variable land surface (e.g., elevation, heating/cooling, CAP). This method proposed here allows predicting landsurface influences on $T$ as a function of topography (like we did here) and it can potentially be extended to include other 

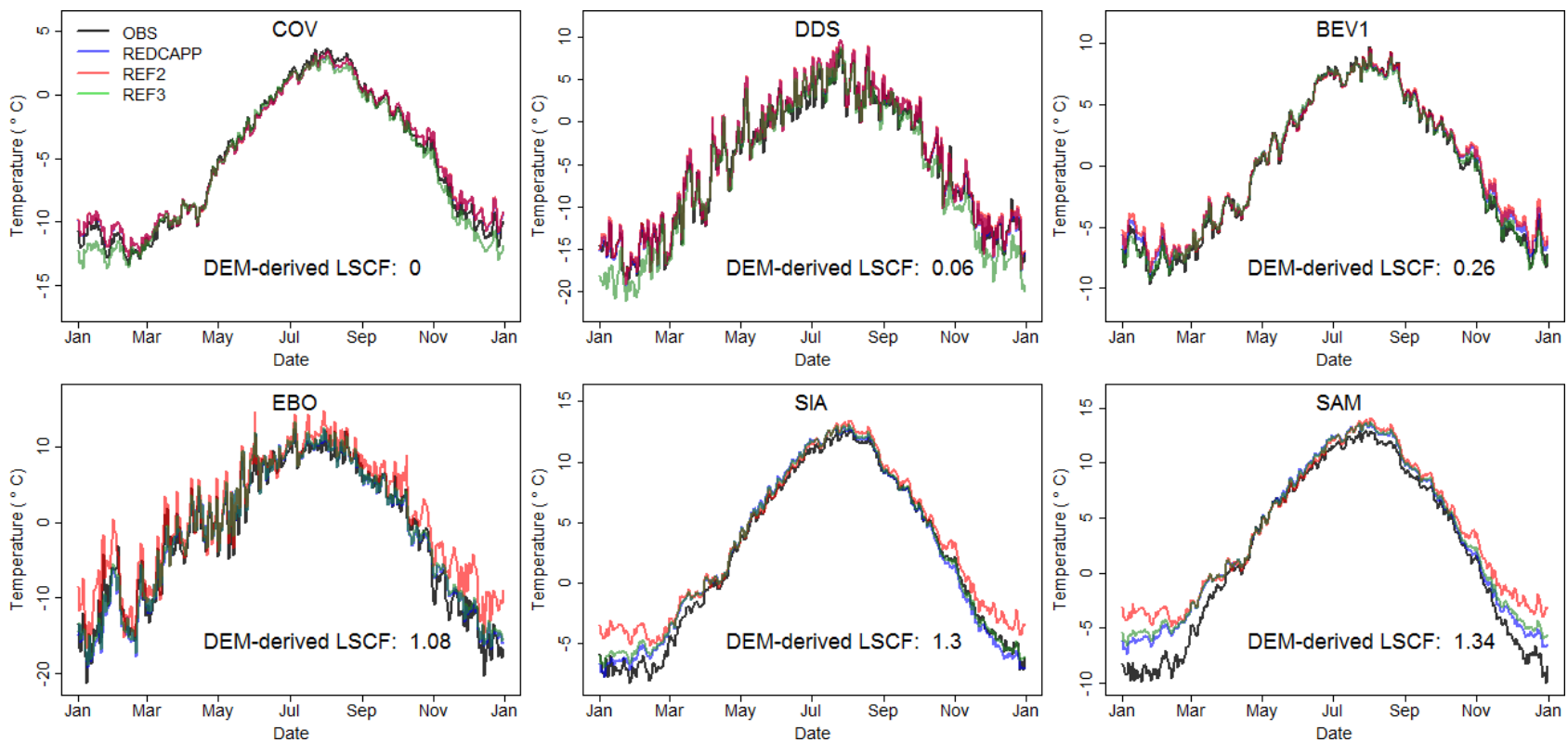

Figure 13. Comparison of REF2, REF3 and REDCAPP with time series at selected stations. The daily temperatures present are averaged based on all available years (Table 3); the shorter time series for EBO explains the larger variation in the plot.

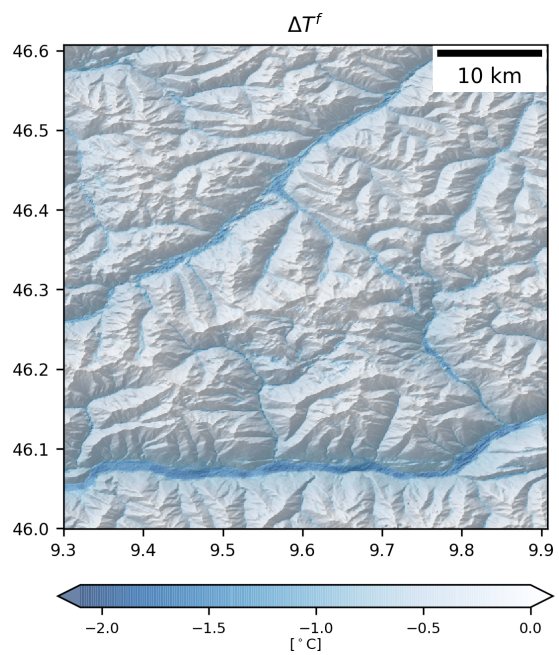

Figure 14. The fine scale of land-surface influence $\left(\Delta T^{\mathrm{f}}\right)$ for the test area.

surface conditions (e.g., snow, canopy, soil moisture), which are considered important (Lin et al., 2016; Liston and Elder, 2006).

\section{Conclusions}

We describe and test a downscaling method for near-surface air temperature. It derives $\Delta T$ from coarse-scale atmospheric model data as a proxy of the effect that the land surface has on near-surface air temperature. The magnitude of this effect is adjusted at the fine scale based on geomorphometric char- acteristics derived from a fine scale of a DEM. The results from the new method are evaluated with 395 stations in two mountain ranges, leading to these conclusions:

1. The proxy $\Delta T$ is suitable for parameterizing CAP and surface effects.

2. The land-surface correction factor LSCF can be predicted from a fine-scale DEM where $\sim 70 \%$ of the variance in directly fitted LSCF could be explained by the parameterization.

3. REDCAPP improves downscaling when compared with reference methods. This is primarily because the advantages of REF2 and REF3 are combined.

4. The transfer of REDCAPP parameters between mountain ranges is difficult and at present, separate fitting parameters in new regions are recommended.

REDCAPP can produce daily, high-resolution (here $\sim 90 \mathrm{~m}$ ) gridded fields of near-surface air temperature in mountains. This can provide input for other models simulating phenomena related to, e.g., hydrology, permafrost and ecology. The input data are not limited to ERA-Interim and could be extended to other reanalyses such as CFSR, NCEP, MERRA or 20CRV2.

Code and data availability. REDCAPP, written in Python, is available in the Supplement and updates will be available via GitHub (https://github.com/geocryology/REDCAPP). The observation and reanalysis data used are not openly available online but can be requested from the sources cited for research purposes. 


\section{Appendix A: Nomenclature}

In this study, $T$ refers to air temperatures, subscripts identify the source (obs: observation; sa: surface analysis; pl: pressure level) and superscripts identify the elevation (c: coarse scale, f: fine scale). Coarse-scale elevation refers to the topography used by the reanalysis; fine-scale refers to the DEM used for downscaling. Observations refer to mean daily air temperature and are assumed to be at the elevation of fine-scale topography. The surface analysis fields in the reanalysis are given at the elevation of the coarse-scale topography (as obtained from invariant geopotential ERAInterim file by Eq. 3); pl represents air temperature derived from pressure levels and can be either. The following list provides the definitions of symbols for REDCAPP.

$\begin{array}{llr}\text { Symbol } & \text { Name } & \text { Unit } \\ T & \text { Near-surface air temperature } & { }^{\circ} \mathrm{C} \\ T_{\mathrm{obs}} & \text { Observational surface air temperature } & { }^{\circ} \mathrm{C} \\ T_{\mathrm{sa}} & \text { 2 m air temperature at the elevation of coarse scale } & { }^{\circ} \mathrm{C} \\ T_{\mathrm{pl}} & \text { Air temperature of pressure level in reanalysis, known as upper-air temperature } & { }^{\circ} \mathrm{C} \\ T_{\mathrm{pl}}^{\mathrm{c}} & \text { Air temperature of pressure level at the elevation of coarse scale } & { }^{\circ} \mathrm{C} \\ T_{\mathrm{pl}}^{\mathrm{f}} & \text { Air temperature of pressure level at the elevation of fine scale } & { }^{\circ} \mathrm{C} \\ \Delta T & \text { Land-surface influences on surface air temperature } & { }^{\circ} \mathrm{C} \\ \Delta T^{\mathrm{c}} & \text { Land-surface influences on surface air temperature at elevation of coarse scale } & { }^{\circ} \mathrm{C} \\ \Delta T^{\mathrm{f}} & \text { Land-surface influences on surface air temperature at elevation of fine scale } & { }^{\circ} \mathrm{C} \\ \mathrm{LSCF} & \text { Land-surface correction factor } & - \\ \alpha & \text { Fractional influence of surface effects on air temperature } & - \\ \beta & \text { Influences of cold air pooling on air temperature } & - \\ h & \text { Scaled hypsometric position } & - \\ H & \text { Hypsometric position } & - \\ v & \text { Degree of valleyness } & - \\ \mathrm{MRVBF} & \text { Multiresolution valley bottom flatness index } & - \\ V & \text { Normalized multiresolution valley bottom flatness index } & - \\ R & \text { Elevation range in a prescribed neighborhood } & \mathrm{m}\end{array}$




\section{Appendix B: Topography factors}

\section{B1 Hypsometric position}

To improve computational effectiveness, hypsometric position is derived by using a lower-resolution DEM ( 15 arcsec or $\sim 450 \mathrm{~m}$ ) derived by aggregating the fine-scale DEM (Fig. B1). Figure B2 presents the comparison of hypsometric position obtained from original fine-scale ( 3 arcsec or $\sim 90 \mathrm{~m}$ ) and aggregated DEMs in the Swiss Alps and in the Qilian Mountains.

\section{B2 Multiresolution index of valley bottom flatness}

The choice of suitable parameters for MRVBF is affected by the resolution of the input DEM as well as different landscape characteristics and applications (Gallant and Dowling, 2003). In response to the cold air pooling movement, the slope threshold is adjusted from the original value of 16 to $50 \%$ in this study. Figure B3 compares MRVBF using a slope threshold of 50 and $16 \%$ (original paper) in the Alps and the Qilian Mountains. The results indicate that MRVBF is smoother when using the larger threshold and hence likely describes cold air movement better. The threshold value of 50 was chosen after considerable tests and comparisons but ultimately remains a subjective choice at this time.

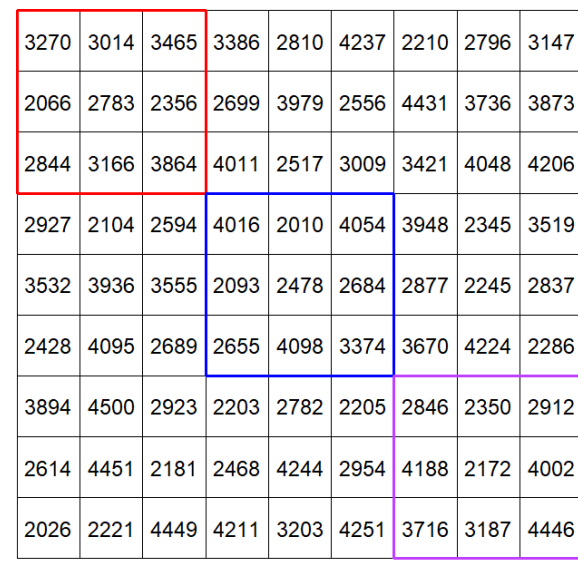

DEM of 1 arcsec

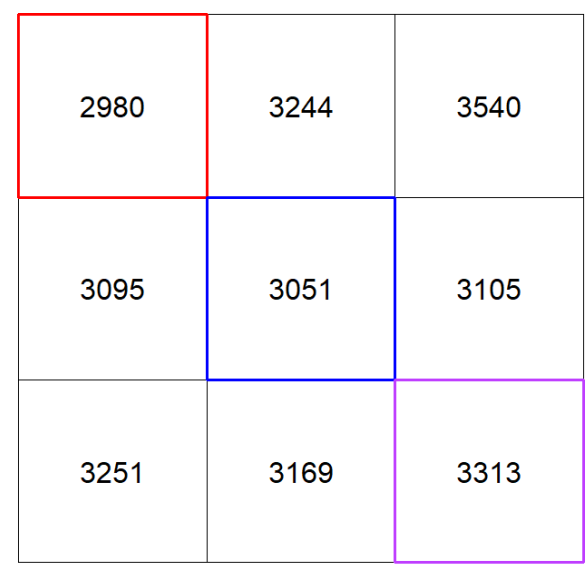

DEM of 3 arcsec

Figure B1. Schematic illustration of DEM aggregation from a grid spacing of 1 to 3 arcsec by averaging. Numbers in the pixels are elevations in meters. In the hypsometric simulation, the DEM with a grid spacing of 15 arcsec is derived using the same method. 

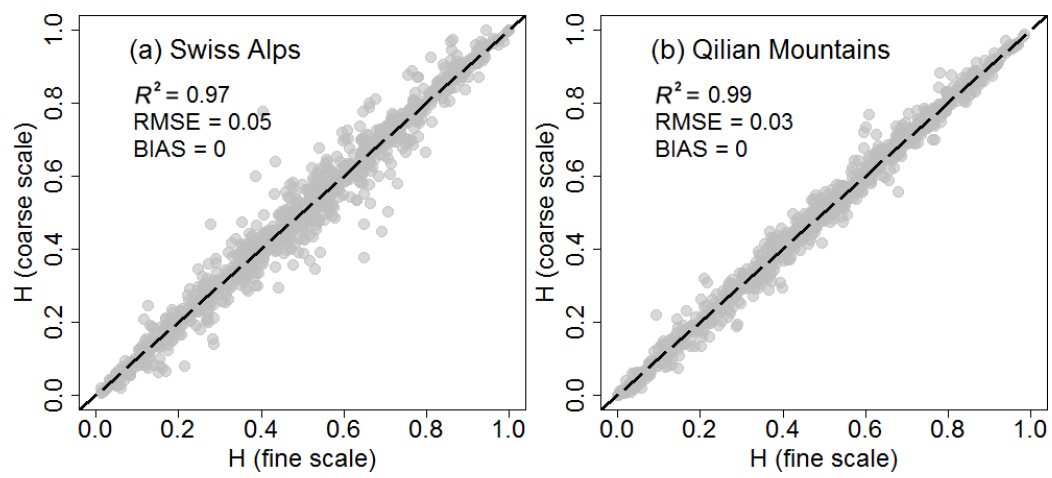

Figure B2. Comparison of hypsometric position derived from coarse-scale ( 15 arcsec) and fine-scale ( 3 arcsec) DEMs based on a random sample of 1000 points.

(a) Test area $(50 \%)$

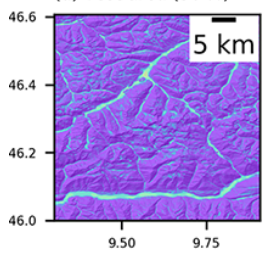

(e) Swiss Alps ( $50 \%$ )

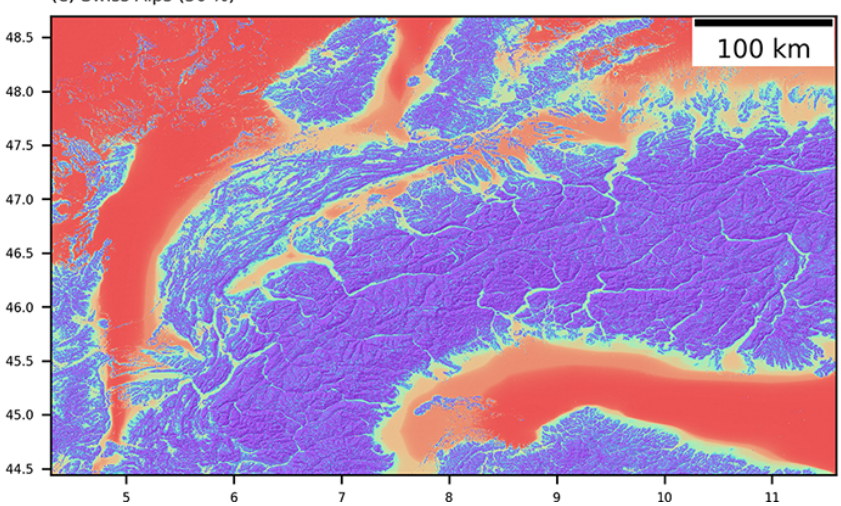

(b) Test area (16\%)

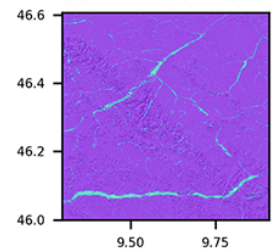

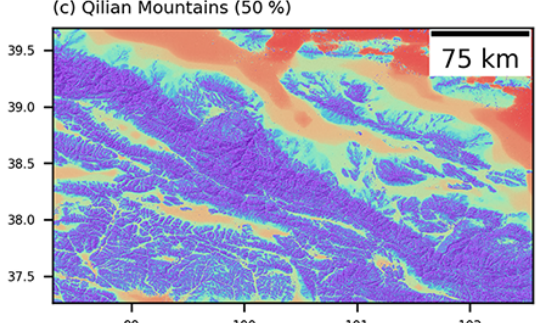

(f) Swiss Alps (16\%)

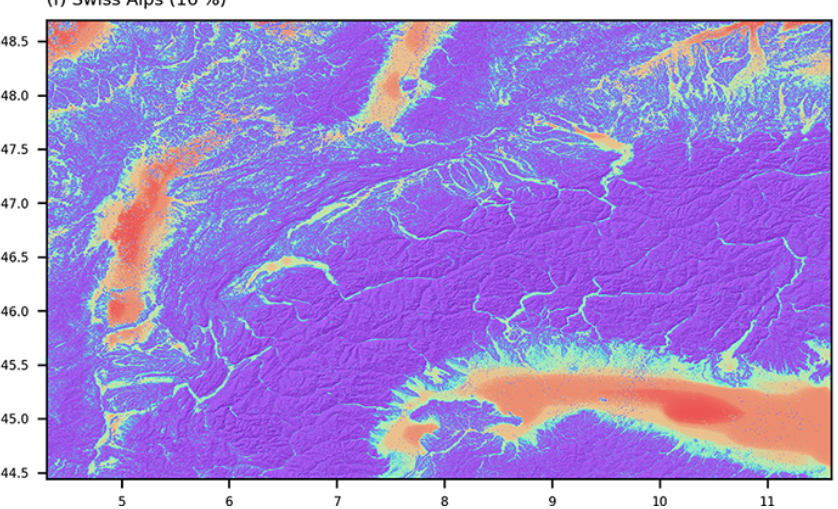

Figure B3. Original MRVBF in the test area, Swiss Alps and the Qilian Mountains by using a slope threshold of 50 and $16 \%$. 


\section{The Supplement related to this article is available online at https://doi.org/10.5194/gmd-10-2905-2017- supplement.}

Author contributions. BC carried out this study by analyzing data, developing most of the model code, performing the simulations and by structuring as well as writing the paper. SG conceived and guided the project, designed part of the code and contributed to structuring and writing the paper. $\mathrm{TZ}$ contributed to the writing of the paper.

Competing interests. The authors declare that they have no conflict of interest.

Acknowledgements. We would like to express our gratitude to John C. Gallant for his help with the multiresolution index of valley bottom flatness. Station data in Switzerland are provided by the Swiss Federal Office of Meteorology and Climatology (MeteoSwiss) and Inter-cantonal Measurement and Information System (IMIS) from the WSL Institute for Snow and Avalanche Research SLF. The authors would like to thank Joel Fiddes for help with the IMIS dataset. We would also like to thank the Heihe Watershed Allied Telemetry Experimental Research (HIWATER) project and Third Pole Environment Database for providing air temperature in the Qilian Mountains. We thank ECMWF for the ERA-Interim reanalysis data. This study was supported by the National Natural Science Foundation of China (91325202), the National Key Scientific Research Program of China (2013CBA01802), partly by the Fundamental Research Funds for the Central Universities (China) and by the projected of "Quantifying the Hidden Thaw" funded by the Canada Foundation for Innovation (CFI). The ASTER dataset is downloaded from http://gdex.cr.usgs.gov/gdex/.

Edited by: Patrick Jöckel

Reviewed by: two anonymous referees

\section{References}

Bao, X. and Zhang, F.: Evaluation of NCEP-CFSR, NCEP-NCAR, ERA-Interim, and ERA-40 Reanalysis Datasets against Independent Sounding Observations over the Tibetan Plateau, J. Climate, 26, 206-214, https://doi.org/10.1175/JCLI-D-12-00056.1, 2013.

Berrisford, P., Dee, D., Poli, P., Brugge, R., Fielding, K., Fuentes, M., Kallberg, P., Kobayashi, S., Uppala, S., and Simmons, A.: The ERA-Interim archive, version 2.0, Technical report, ECMWF, 2011

Bürger, G., Murdock, T. Q., Werner, A. T., Sobie, S. R., and Cannon, A. J.: Downscaling Extremes - An Intercomparison of Multiple Statistical Methods for Present Climate, J. Climate, 25, 43664388, https://doi.org/10.1175/JCLI-D-11-00408.1, 2012.

Chen, G., Iwasaki, T., Qin, H., and Sha, W.: Evaluation of the Warm-Season Diurnal Variability over East Asia in Recent Reanalyses JRA-55, ERA-Interim, NCEP CFSR, and NASA MERRA, J. Climate, 27, 5517-5537, https://doi.org/10.1175/JCLI-D-14-00005.1, 2014.
Chen, Y., Yang, K., He, J., Qin, J., Shi, J., Du, J., and He, Q.: Improving land surface temperature modeling for dry land of China, J. Geophys. Res.-Atmos., 116, d20104, https://doi.org/10.1029/2011JD015921, 2011.

Chu, J. T., Xia, J., Xu, C.-Y., and Singh, V. P.: Statistical downscaling of daily mean temperature, pan evaporation and precipitation for climate change scenarios in Haihe River, China, Theor. Appl. Climatol., 99, 149-161, https://doi.org/10.1007/s00704009-0129-6, 2010.

Compo, G. P., Whitaker, J. S., Sardeshmukh, P. D., Matsui, N., Allan, R. J., Yin, X., Gleason, B. E., Vose, R. S., Rutledge, G., Bessemoulin, P., Brönnimann, S., Brunet, M., Crouthamel, R. I., Grant, A. N., Groisman, P. Y., Jones, P. D., Kruk, M. C., Kruger, A. C., Marshall, G. J., Maugeri, M., Mok, H. Y., Nordli, Ø., Ross, T. F., Trigo, R. M., Wang, X. L., Woodruff, S. D., and Worley, S. J.: The Twentieth Century Reanalysis Project, Q. J. Roy. Meteor. Soc., 137, 1-28, https://doi.org/10.1002/qj.776, 2011.

Daly, C.: Guidelines for assessing the suitability of spatial climate data sets, Int. J. Climatol., 26, 707-721, https://doi.org/10.1002/joc.1322, 2006.

Daly, C., Taylor, G. H., Gibson, W. P., Parzybok, T. W., Johnson, G. L., and Pasteris, P. A.: High-quality spatial climate data sets for the United States and beyond, T. ASAE, 43, 1957-1962, 2000.

Daly, C., Gibson, W., Taylor, G., Johnson, G., and Pasteris, P.: A knowledge-based approach to the statistical mapping of climate, Clim. Res., 22, 99-113, https://doi.org/10.3354/cr022099, 2002.

Dee, D. P., Uppala, S. M., Simmons, A. J., Berrisford, P., Poli, P., Kobayashi, S., Andrae, U., Balmaseda, M. A., Balsamo, G., Bauer, P., Bechtold, P., Beljaars, A. C. M., van de Berg, L., Bidlot, J., Bormann, N., Delsol, C., Dragani, R., Fuentes, M., Geer, A. J., Haimberger, L., Healy, S. B., Hersbach, H., Hølm, E. V., Isaksen, L., Kållberg, P., Köhler, M., Matricardi, M., McNally, A. P., Monge-Sanz, B. M., Morcrette, J.-J., Park, B.-K., Peubey, C., de Rosnay, P., Tavolato, C., Thépaut, J.-N., and Vitart, F.: The ERA-Interim reanalysis: configuration and performance of the data assimilation system, Q. J. Roy. Meteor. Soc., 137, 553-597, https://doi.org/10.1002/qj.828, 2011.

Dimri, A. P.: Impact of subgrid scale scheme on topography and landuse for better regional scale simulation of meteorological variables over the western Himalayas, Clim. Dynam., 32, 565-574, https://doi.org/10.1007/s00382-008-0453-z, 2009.

Fiddes, J. and Gruber, S.: TopoSCALE v.1.0: downscaling gridded climate data in complex terrain, Geosci. Model Dev., 7, 387-405, https://doi.org/10.5194/gmd-7-387-2014, 2014.

Fiddes, J., Endrizzi, S., and Gruber, S.: Large-area land surface simulations in heterogeneous terrain driven by global data sets: application to mountain permafrost, The Cryosphere, 9, 411-426, https://doi.org/10.5194/tc-9-411-2015, 2015.

Fowler, H. J., Blenkinsop, S., and Tebaldi, C.: Linking climate change modelling to impacts studies: recent advances in downscaling techniques for hydrological modelling, Int. J. Climatol., 27, 1547-1578, https://doi.org/10.1002/joc.1556, 2007.

Gallant, J. C. and Dowling, T. I.: A multiresolution index of valley bottom flatness for mapping depositional areas, Water Resour. Res., 39, 1347, https://doi.org/10.1029/2002WR001426, 2003.

Gao, L., Bernhardt, M., and Schulz, K.: Elevation correction of ERA-Interim temperature data in complex terrain, Hydrol. Earth 
Syst. Sci., 16, 4661-4673, https://doi.org/10.5194/hess-16-46612012, 2012.

Giorgi, F., Francisco, R., and Pal, J.: Effects of a SubgridScale Topography and Land Use Scheme on the Simulation of Surface Climate and Hydrology. Part I: Effects of Temperature and Water Vapor Disaggregation, J. Hydrometeorol., 4, 317-333, https://doi.org/10.1175/15257541(2003)4<317:EOASTA>2.0.CO;2, 2003.

Gruber, S.: Derivation and analysis of a high-resolution estimate of global permafrost zonation, The Cryosphere, 6, 221-233, https://doi.org/10.5194/tc-6-221-2012, 2012.

Gupta, A. S. and Tarboton, D. G.: A tool for downscaling weather data from large-grid reanalysis products to finer spatial scales for distributed hydrological applications, Environ. Model. Softw., 84, 50-69, https://doi.org/10.1016/j.envsoft.2016.06.014, 2016.

Hagemann, S., Machenhauer, B., Jones, R., Christensen, O. B., Déqué, M., Jacob, D., and Vidale, P. L.: Evaluation of water and energy budgets in regional climate models applied over Europe, Clim. Dynam., 23, 547-567, https://doi.org/10.1007/s00382004-0444-7, 2004.

Harris, I., Jones, P., Osborn, T., and Lister, D.: Updated high-resolution grids of monthly climatic observations the CRU TS3.10 Dataset, Int. J. Climatol., 34, 623-642, https://doi.org/10.1002/joc.3711, 2014.

Hay, L. and Clark, M.: Use of statistically and dynamically downscaled atmospheric model output for hydrologic simulations in three mountainous basins in the western United States, J. Hydrol., 282, 56-75, https://doi.org/10.1016/S00221694(03)00252-X, 2003.

Hijmans, R. J., Cameron, S. E., Parra, J. L., Jones, P. G., and Jarvis, A.: Very high resolution interpolated climate surfaces for global land areas, Int. J. Climatol., 25, 1965-1978, https://doi.org/10.1002/joc.1276, 2005.

Hodges, K. I., Lee, R. W., and Bengtsson, L.: A Comparison of Extratropical Cyclones in Recent Reanalyses ERA-Interim, NASA MERRA, NCEP CFSR, and JRA-25, J. Climate, 24, 4888-4906, https://doi.org/10.1175/2011JCLI4097.1, 2011.

Hofer, M., Mölg, T., Marzeion, B., and Kaser, G.: Empiricalstatistical downscaling of reanalysis data to high-resolution air temperature and specific humidity above a glacier surface (Cordillera Blanca, Peru), J. Geophys. Res.-Atmos., 115, d12120, https://doi.org/10.1029/2009JD012556, 2010.

Jones, P. and Kelly, P.: The spatial and temporal characteristics of Northern Hemisphere surface air temperature variations, J. Climatol., 3, 243-252, 1983.

Kiefer, M. T. and Zhong, S.: The role of forest cover and valley geometry in cold-air pool evolution, J. Geophys. Res.-Atmos., 120, 8693-8711, https://doi.org/10.1002/2014JD022998, 2015.

Kistler, R., Collins, W., Saha, S., White, G., Woollen, J., Kalnay, E., Chelliah, M., Ebisuzaki, W., Kanamitsu, M., Kousky, V., van den Dool, H., Jenne, R., and Fiorino, M.: The NCEP-NCAR 50-Year Reanalysis: Monthly Means CD-ROM and Documentation, B. Am. Meteorol. Soc., 82, 247-267, https://doi.org/10.1175/15200477(2001)082<0247:TNNYRM>2.3.CO;2, 2001.

Lareau, N. P., Crosman, E., Whiteman, C. D., Horel, J. D., Hoch, S. W., Brown, W. O. J., and Horst, T. W.: The Persistent Cold-Air Pool Study, B. Am. Meteorol. Soc., 94, 51-63, https://doi.org/10.1175/BAMS-D-11-00255.1, 2013.
Lewkowicz, A. G. and Bonnaventure, P. P.: Equivalent Elevation: A New Method to Incorporate Variable Surface Lapse Rates into Mountain Permafrost Modelling, Permafrost Periglac., 22, 153162, https://doi.org/10.1002/ppp.720, 2011.

Li, X., Cheng, G., Liu, S., Xiao, Q., Ma, M., Jin, R., Che, T., Liu, Q., Wang, W., Qi, Y., Wen, J., Li, H., Zhu, G., Guo, J., Ran, Y., Wang, S., Zhu, Z., Zhou, J., Hu, X., and Xu, Z.: Heihe Watershed Allied Telemetry Experimental Research (HiWATER): Scientific Objectives and Experimental Design, B. Am. Meteorol. Soc., 94, 1145-1160, https://doi.org/10.1175/BAMS-D-1200154.1, 2013.

Lin, P., Wei, J., Yang, Z.-L., Zhang, Y., and Zhang, K.: Snow data assimilation-constrained land initialization improves seasonal temperature prediction, Geophysical Res. Lett., 43, 11423 11432, https://doi.org/10.1002/2016GL070966, 2016.

Liston, G. E. and Elder, K.: A Meteorological Distribution System for High-Resolution Terrestrial Modeling (MicroMet), J. Hydrometeorol., 7, 217-234, https://doi.org/10.1175/JHM486.1, 2006.

Lundquist, J. D. and Cayan, D. R.: Surface temperature patterns in complex terrain: Daily variations and long-term change in the central Sierra Nevada, California, J. Geophys. Res-.Atmos., 112, d11124, https://doi.org/10.1029/2006JD007561, 2007.

Mahrt, L., Vickers, D., Nakamura, R., Soler, M. R., Sun, J., Burns, S., and Lenschow, D.: Shallow Drainage Flows, Bound.-Lay. Meteorol., 101, 243-260, https://doi.org/10.1023/A:1019273314378, 2001.

Maraun, D., Wetterhall, F., Ireson, A. M., Chandler, R. E., Kendon, E. J., Widmann, M., Brienen, S., Rust, H. W., Sauter, T., Themeß1, M., Venema, V. K. C., Chun, K. P., Goodess, C. M., Jones, R. G., Onof, C., Vrac, M., and Thiele-Eich, I.: Precipitation downscaling under climate change: Recent developments to bridge the gap between dynamical models and the end user, Rev. Geophys., 48, rG3003, https://doi.org/10.1029/2009RG000314, 2010.

Meyer, D., Tachikawa, T., Kaku, M., Iwasak, A., Gesch, D., Oimoen, M., Zhang, Z., Danielson, J., Krieger T., Curtis, B., Haase, J., Abrams, M., Crippen, R., and Carabajal, C.: ASTER Global Digital Elevation Model Version 2 - Summary of Validation Results, Japan-US ASTER Science Team, 1-26, 2011.

Minder, J. R., Mote, P. W., and Lundquist, J. D.: Surface temperature lapse rates over complex terrain: Lessons from the Cascade Mountains, J. Geophys. Res.-Atmos., 115, d14122, https://doi.org/10.1029/2009JD013493, 2010.

Mokhov, I. I. and Akperov, M. G.: Tropospheric lapse rate and its relation to surface temperature from reanalysis data, Izvestiya, Atmos. Ocean. Phys., 42, 430-438, https://doi.org/10.1134/S0001433806040037, 2006.

Mugford, R. I., Christoffersen, P., and Dowdeswell, J. A.: Evaluation of the ERA-Interim Reanalysis for Modelling Permafrost on the North Slope of Alaska ERA-Interim Validation, in: Proceedings of the 10th International Conference on Permafrost, 25-29 June 2012, Salekhard, Russia, 2012.

Souvignet, M., Gaese, H., Ribbe, L., Kretschmer, N., and Oyarzún, R.: Statistical downscaling of precipitation and temperature in north-central Chile: an assessment of possible climate change impacts in an arid Andean watershed, Hydrolog. Sci. J., 55, 4157, https://doi.org/10.1080/02626660903526045, 2010. 
Storn, R. and Price, K.: Differential Evolution - A Simple and Efficient Heuristic for global Optimization over Continuous Spaces, J. Global Optim., 11, 341-359, https://doi.org/10.1023/A:1008202821328, 1997.

Tabony, R. C.: Relations between minimum temperature and topography in great britain, J. Climatol., 5, 503-520, https://doi.org/10.1002/joc.3370050504, 1985.

Tachikawa, T., Hato, M., Kaku, M., and Iwasaki, A.: Characteristics of ASTER GDEM version 2, in: Geoscience and Remote Sensing Symposium (IGARSS), 2011 IEEE International, 36573660, 2011.

Thornton, P. E., Running, S. W., and White, M. A.: Generating surfaces of daily meteorological variables over large regions of complex terrain, J. Hydrol., 190, 214-251, https://doi.org/10.1016/S0022-1694(96)03128-9, 1997. van de Berg, W. J. and Medley, B.: Brief Communication: Upper-air relaxation in RACMO2 significantly improves modelled interannual surface mass balance variability in Antarctica, The Cryosphere, 10, 459-463, https://doi.org/10.5194/tc10-459-2016, 2016.

Whiteman, C. D., Zhong, S., Shaw, W. J., Hubbe, J. M., Bian, X., and Mittelstadt, J.: Cold Pools in the Columbia Basin, Weather and Forecasting, 16, 432-447, https://doi.org/10.1175/15200434(2001)016<0432:CPITCB>2.0.CO;2, 2001.

Yang, T., Li, H., Wang, W., Xu, C.-Y., and Yu, Z.: Statistical downscaling of extreme daily precipitation, evaporation, and temperature and construction of future scenarios, Hydrol. Process., 26, 3510-3523, https://doi.org/10.1002/hyp.8427, 2012. 